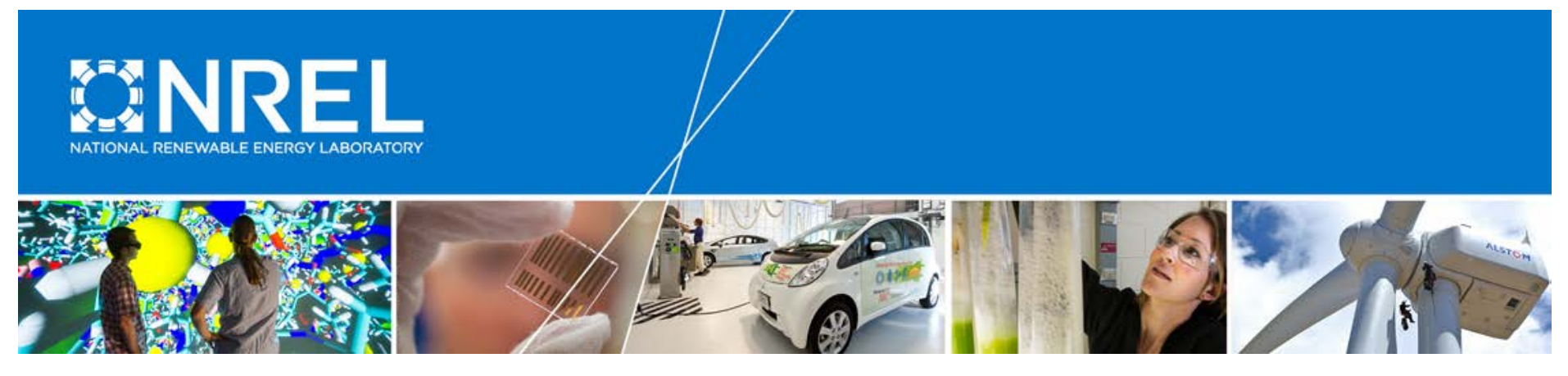

\title{
Application of Horizontal Well Completion Techniques to Enhanced Geothermal Systems: Final Report
}

\section{October 2015 - September 2016}

Alfred Eustes, Azra Tutuncu, Reed Baker, Xiexiaomeng (Jack) Hu, and Jeffrey Olson Colorado School of Mines Golden, Colorado

NREL Technical Monitor: Chad Augustine

Prepared under Subcontract No. UGA-0-41025-88

NREL is a national laboratory of the U.S. Department of Energy Office of Energy Efficiency \& Renewable Energy Operated by the Alliance for Sustainable Energy, LLC

This report is available at no cost from the National Renewable Energy Laboratory (NREL) at www.nrel.gov/publications.

Subcontract Report

NREL/SR-6A20-71201

August 2018 


\title{
Application of Horizontal Well Completion Techniques to Enhanced Geothermal Systems: Final Report
}

\section{October 2015 - September 2016}

\author{
Alfred Eustes, Azra Tutuncu, Reed Baker, \\ Xiexiaomeng (Jack) Hu, and Jeffrey Olson \\ Colorado School of Mines \\ Golden, Colorado
}

NREL Technical Monitor: Chad Augustine

Prepared under Subcontract No. UGA-0-41025-88

\section{Suggested Citation}

Eustes, Alfred, Azra Tutuncu, Reed Baker, Xiexiaomeng (Jack) Hu, and Jeffrey Olson. 2018. Application of Horizontal Well Completion Techniques to Enhanced Geothermal Systems: Final Report: October 2015 - September 2016. Golden, CO: National Renewable Energy Laboratory. NREL/SR-6A20-71201.

www.nrel.gov/docs/fy180sti/71201.pdf.

NREL is a national laboratory of the U.S. Department of Energy Office of Energy Efficiency \& Renewable Energy Operated by the Alliance for Sustainable Energy, LLC

This report is available at no cost from the National Renewable Energy Laboratory (NREL) at www.nrel.gov/publications.

National Renewable Energy Laboratory 15013 Denver West Parkway Golden, CO 80401

303-275-3000 • www.nrel.gov

\section{Subcontract Report}

NREL/SR-6A20-71201

August 2018

Contract No. DE-AC36-08G028308 


\section{NOTICE}

This work was authored by the National Renewable Energy Laboratory, operated by Alliance for Sustainable Energy, LLC, for the U.S. Department of Energy (DOE) under Contract No. DE-AC36-08G028308. Funding provided by the Department of Energy Geothermal Technologies Office. The views expressed in the article do not necessarily represent the views of the DOE or the U.S. Government.

This report is available at no cost from the National Renewable Energy Laboratory (NREL) at www.nrel.gov/publications.

U.S. Department of Energy (DOE) reports produced after 1991 and a growing number of pre-1991 documents are available free via www.OSTI.gov.

Cover Photos by Dennis Schroeder: (left to right) NREL 26173, NREL 18302, NREL 19758, NREL 29642, NREL 19795.

NREL prints on paper that contains recycled content. 


\section{List of Acronyms}

2-D

3-D

API

bpd

CRA

CSM

CT

DFN

DOE

EGS

ESP

FY

GGBFS

HDR

$\mathrm{HF}$

HPHT

ID

MWe

NF

NREL

NRP

ppf

SAGD

UFM two-dimensional

three-dimensional

American Petroleum Institute

barrels per day

corrosion-resistant alloy

Colorado School of Mines

coiled tubing

discrete fracture network

U.S. Department of Energy

enhanced geothermal system

electric submersible pump

fiscal year

ground granulated blast furnace slag

hot dry rock

hydraulically induced fracture

high-pressure high-temperature

inner diameter

megawatts electricity

natural fracture

National Renewable Energy Laboratory

non-rotating protector

pounds per foot

steam-assisted gravity drainage

Unconventional Fracture Model 


\section{Table of Contents}

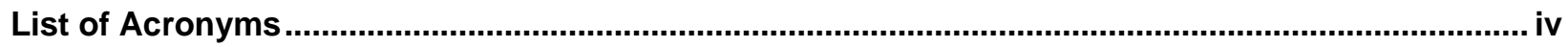

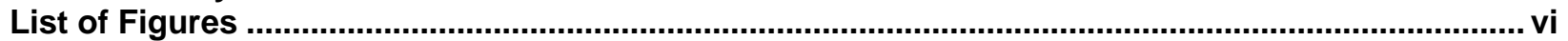

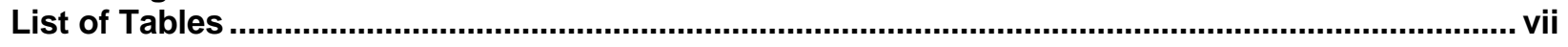

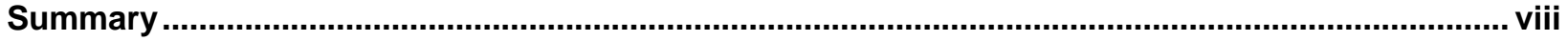

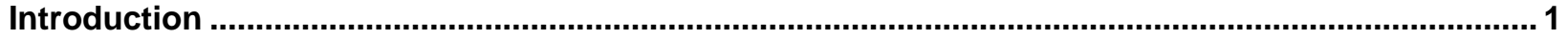

Gas and Oil Technologies Applicable to Geothermal Setting............................................................ 1

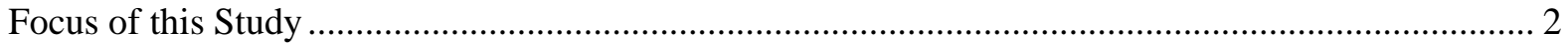

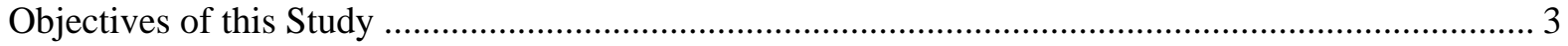

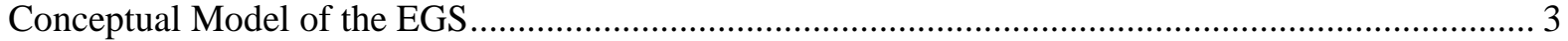

Enhanced Geothermal System Requirements and Modeling...........................................................6

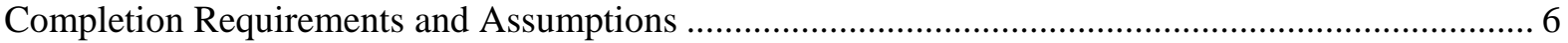

Summary of EGS and Well Assumptions and Requirements .......................................................... 7

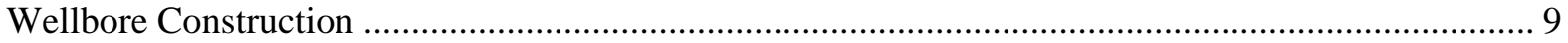

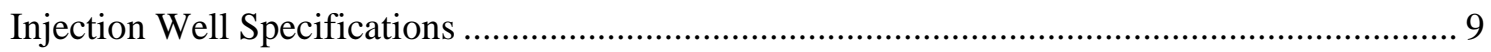

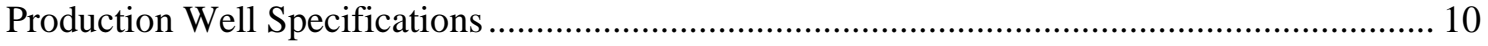

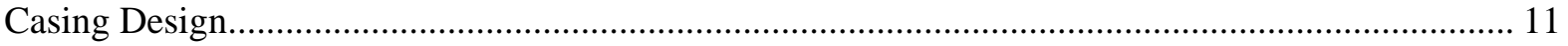

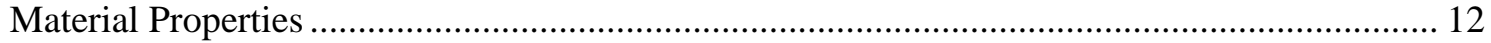

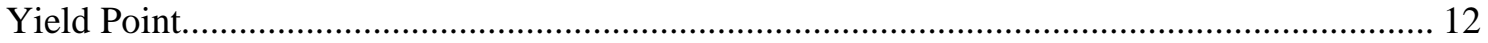

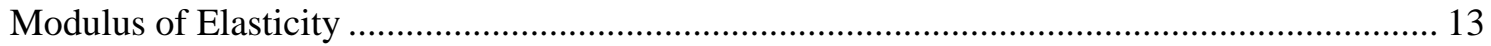

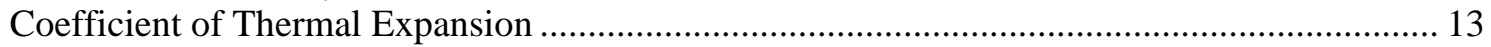

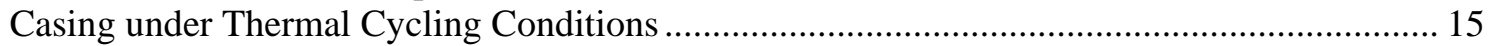

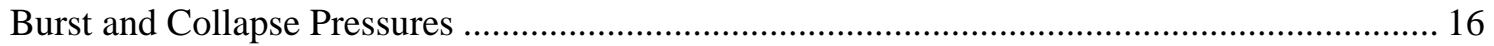

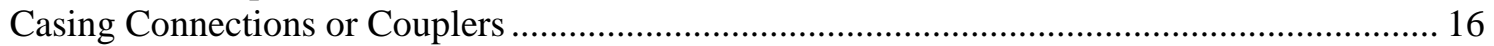

Finite-Element Modeling of Axial Loading of Proposed Casing Designs .................................. 17

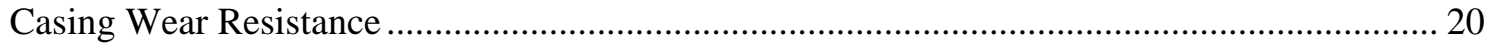

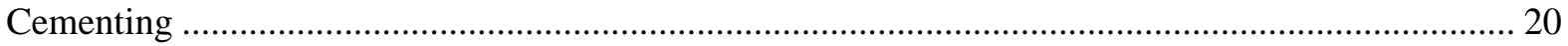

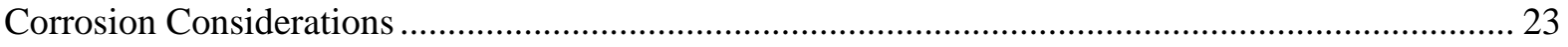

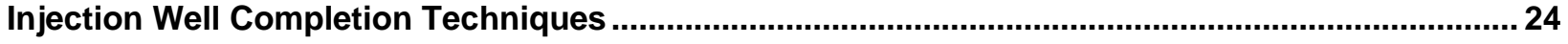

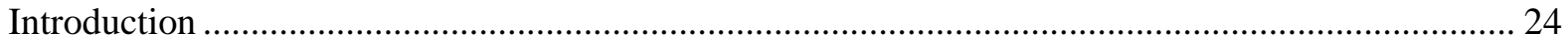

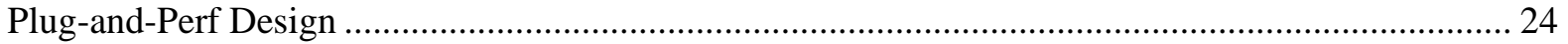

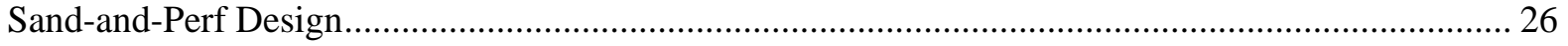

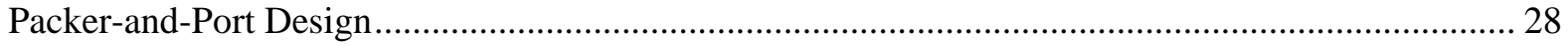

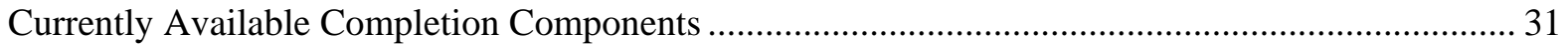

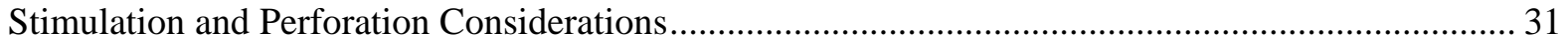

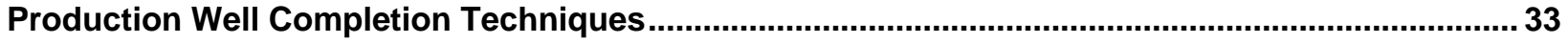

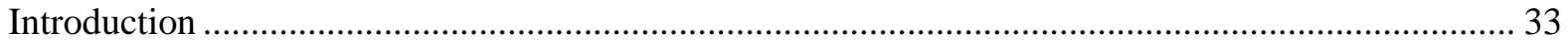

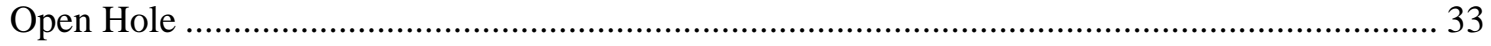

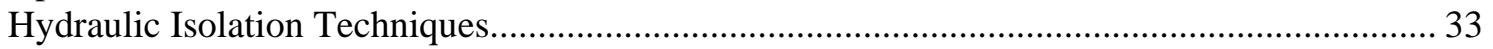

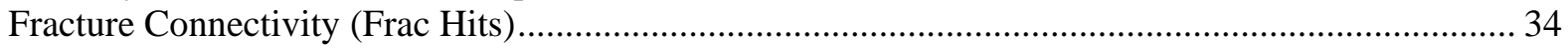

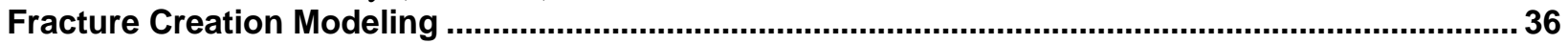

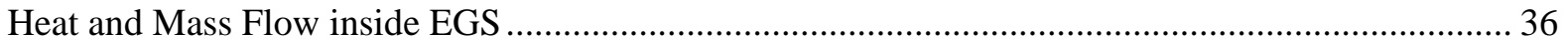

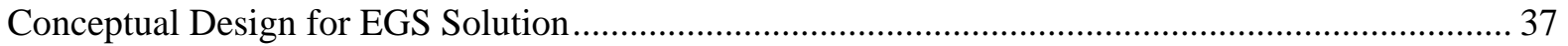

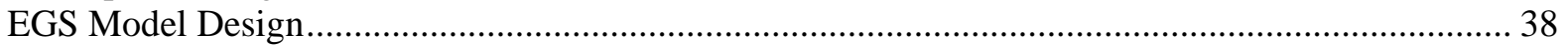

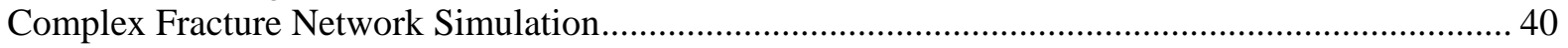

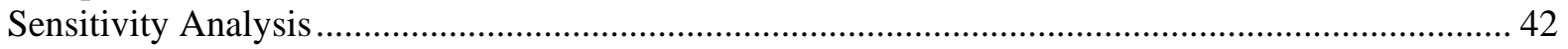

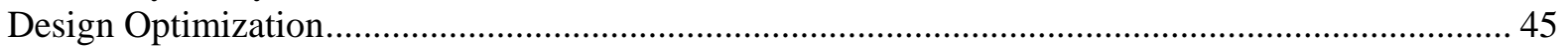

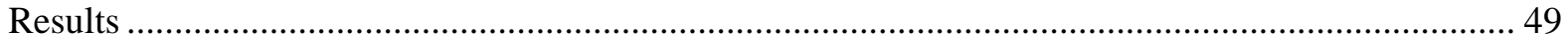

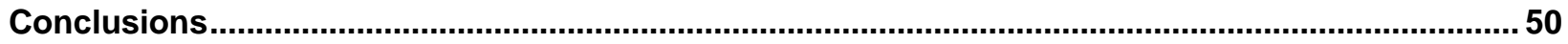

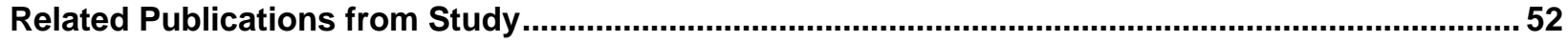

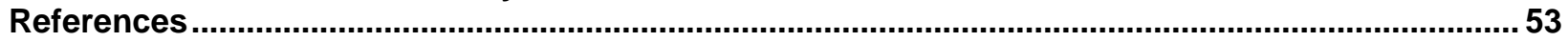




\section{List of Figures}

Figure 1. Diagram of a steam-assisted gravity drainage (SAGD) system. ............................................... 2 Figure 2. Generalized top-down look at the proposed EGS system. Red arrows show production wells and

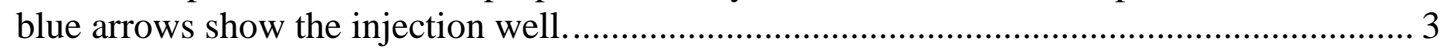

Figure 3. Vertical section of proposed wellbore trajectory .................................................................. 7

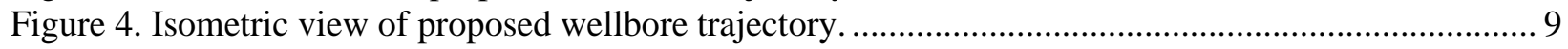

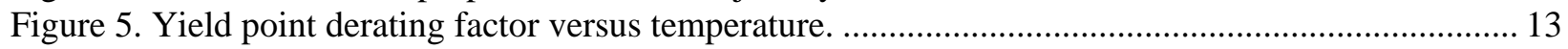

Figure 6. Modulus of elasticity versus temperature................................................................................ 14

Figure 7. Thermal expansion coefficient versus temperature. ............................................................... 14

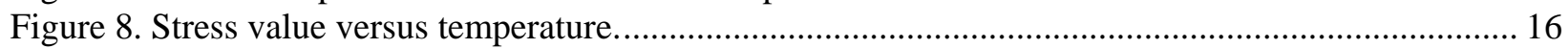

Figure 9. Model of 9-5/8" casing is in the dotted-box section. The rest of the casing is assumed to be

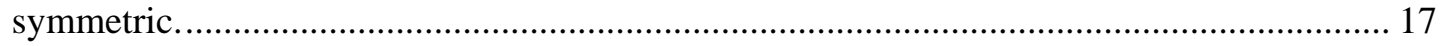

Figure 10. Example output with stress levels (red is high, green is low) .............................................. 17

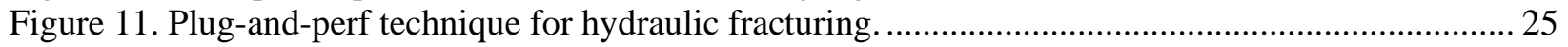

Figure 12. Sand-and-perf technique for hydraulic fracturing. Once a stage has been fractured, it is isolated with packed sand before perforation and stimulation of the next stage (Mathur, et al., 2013).

Figure 13. Multi-zonal packer-and-port system with water-swellable packers (Strategic Oil Solutions,

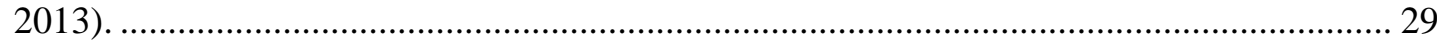

Figure 14. Comparison of shear stimulated volume (left) and rock temperature during circulation (right) for fracture networks created with different stimulation injection rates (Riahi et al., 2014). 37

Figure 15. A multi-stage hydraulic fracture design of 13 perforation clusters with $200-\mathrm{ft}$ spacing (z to y

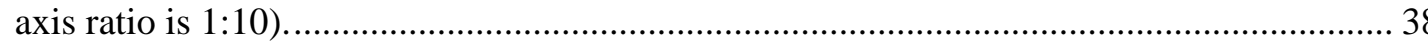

Figure 16. a) Plane top view of simple EGS model consisting of horizontal well with multiple fractures without any natural fractures and stress shadow effect, and b) considering only stress shadow effect.

Figure 17. a) Plane top view of simple EGS model consisting of horizontal well with multiple fractures considering natural fractures and $b$ ) stress shadow effects.

Figure 18. Top view of simulations consisting of horizontal well with multiple fractures assuming stress anisotropy of $500 \mathrm{psi}$ a) without natural fractures, and b) with natural fractures. .................. 42

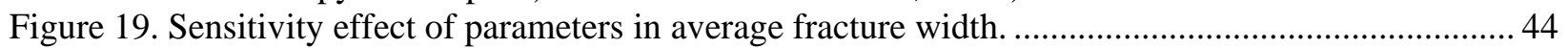

Figure 20. Sensitivity effect of parameters on effective conductivity ............................................... 44

Figure 21. Sensitivity effect on fracture half-length. .......................................................................... 45

Figure 22. 3-D view (a) and top view (b) of EGS design optimization with symmetrical completion order

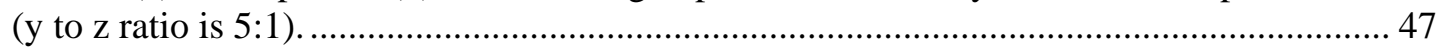

Figure 23. Top view of EGS design optimization with sequential completion order while considering both the positive and negative effects of (a) complex reservoir condition and reduced (b) NF length 


\section{List of Tables}

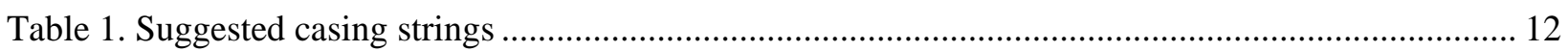

Table 2. Casing cumulative displacement using swellable packers to allow motion................................ 19

Table 3. Input granite material properties used in the reservoir model (EMI 2010 a, b and Morrell 2012)39

Table 4. Default input parameters for fracture simulations (Hu and Tutuncu, 2016)................................ 39

Table 5. Schematic matrix of simulations under EGS model in investigating effects of various parameters

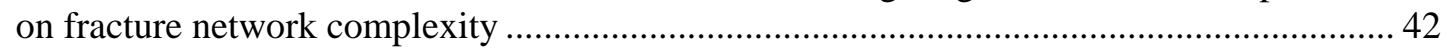

Table 6. Comparison of the input parameters used in base case and range of input parameters used in the sensitivity analysis through simulations................................................................................. 43

Table 7. 2-D DFN design parameters for optimization while considering positive effects of relatively large NF spacing of $120 \mathrm{ft}$ in the model simulation............................................................ 45

Table 8. Treatment parameters for design optimization with positive reservoir condition in achieving successful EGS application in the model simulation ............................................................ 46

Table 9. Simulated numerical results for each stage regarding fracture half-length, average fracture width, and effective conductivity for model simulation in Figure 22. Simulation run using parameters from Table 8 . 


\section{Summary}

This project is a continuation of the FY14 Horizontal Geothermal Completion project sponsored by the U.S. Department of Energy through the National Renewable Energy Laboratory and the Colorado School of Mines. The work is based on the petroleum industry's success in developing unconventional shale plays using horizontal drilling and multi-zonal isolation and stimulation techniques to fracture tight formations, thus enabling the commercial production of oil and gas. Wellbore similarity exists with enhanced geothermal system (EGS) proposals.

The technologies and techniques from the petroleum industry are being stretched to accommodate the higher temperatures, high water flow rates, and large-diameter completions encountered in geothermal settings. In this study, we continue to assess whether well completion techniques used in the unconventional shale industry to create multi-stage fractures can be applied to an enhanced geothermal system, focusing on the fracture construction and completion of the EGS production well.

We assume an EGS consisting of a central horizontal injection well flanked on each side by horizontal production wells, connected to the injection well by multiple fractures. The focus of our study is on creating fracture systems and the required operational parameters.

For the purpose of developing design criteria, we assume a reservoir temperature of $200^{\circ} \mathrm{C}$ $\left(392^{\circ} \mathrm{F}\right)$ and an injection well flow rate of 87,000 barrels per day $(160 \mathrm{~kg} / \mathrm{s})$, corresponding to production well flow rates of 43,500 barrels per day ( $80 \mathrm{~kg} / \mathrm{s})$. This should be adequate to generate about 5 megawatts of electricity (gross) per production well. Further system design requirements — such as fracture lengths, spacing, and number of fractures - were developed using the Gringarten model for an idealized EGS system (Gringarten et al., 1975). We modeled the fracture process using state-of-the-art Schlumberger Mangrove fracture stimulation software.

We used the above assumptions and design criteria from the injection well to develop a production well design, taking into account the following: high flow rates encountered in geothermal systems, thermal cycling, and burst and collapse pressure requirements during production. Our analysis found that a 9-5/8” 53.5 pounds per foot (ppf) P110 casing string meets all design criteria for the horizontal section of the production well. This assumes that no significant corrosion products are entrained in the production stream. If this is not the case, then corrosion-resistant alloys would be required, significantly increasing the cost. A P110 grade is common and is often used in horizontal sections of shale development wells in petroleum operations. However, due to bending stresses, elevated temperatures, and temperature cycling, a non-API premium casing connection should be considered instead of the API Buttress connections typically used in geothermal wells.

We evaluated several zonal isolation systems commonly used in the shale gas industry. Three techniques were evaluated: a "plug-and-perf” design, a "sand-and-perf” design, and a "packerand-port” design.

- A plug-and-perf system uses a cemented casing throughout the length of the injector wellbore. The formation is then stimulated using a multistage fracturing and perforating process. Retrievable or drillable packers are used to isolate stages during stimulation. 
This process is the most technologically advanced technique proposed and provides the best zonal isolation throughout the hydraulic fracturing process-but it is also the most expensive.

- The sand-and-perf system is identical to the plug-and-perf system but replaces packers with sand placed in the casing after stimulation to screen out the stimulated perforated zones and provide zonal isolation. This system is technically simpler than the plug-andperf system. However, it is typically used in vertical wells, where gravity helps deliver sand to its desired location and keep it in place. Placement of sand in a horizontal system could be difficult and could also damage the newly created fractures.

- The packer-and-port completion approach uses an open horizontal hole that zonally isolates areas using external packers and a liner. This method differs from the other two methods by not using cemented casing - thus eliminating the cost and tasks of casing, cementing, and perforating in the horizontal section. The individual stages would be hydraulically fractured one at a time using sliding-sleeve ports or drop-ball valves. A port-and-packer system would likely be the simplest and fastest method to implement from a technical standpoint and has several other advantages, such as avoiding the need to cement the casing in the horizontal section in place. However, the ability of external packers to adequately isolate sections could be problematic because of the difficulty of forming a seal between the outside of the casing and the rough walls of the open borehole.

These three techniques are applicable to a production well as well.

We considered the control of injection or production within a wellbore, which complicates the completion. Given the unequal injection and/or production from various fractures, a control system (i.e., smart well technology) should be considered. Because of the harsh conditions expected in production wells, it is more feasible to install and operate such technology in the injection well.

We reviewed technologies used in these systems to determine if commercially available equipment from the petroleum industry could be used at the temperatures, pressures, and sizes encountered in geothermal settings. Our study found no major technical barriers to employing shale gas multi-zonal completion techniques in a horizontal well in a geothermal setting for EGS development. Temperature limitations of equipment are a concern for all techniques considered. Equipment designed to operate at high temperatures encountered in geothermal systems is commercially available but is generally unproven for geothermal applications. Based on our study, further evaluation of adapting oil and gas completion techniques to EGS is warranted. 


\section{Introduction}

In this report, we explore technology and operational techniques that can be adapted from the oil and gas industry's success in horizontal wellbore placement and multistage stimulation to the completion of horizontal geothermal wells for creating an enhanced geothermal system (EGS). We assess the applicability of the oil and gas completion operations to the higher temperatures, high water-production flow rates, and large-diameter completions required for geothermal electricity generation.

Many potential EGS formations, especially those with ultra-low permeability, tend to share similar characteristics with the unconventional reservoirs in the oil and gas industry. However, differences between the two formations — such as lithology, formation temperature, pore pressure, and in situ stress states - tend to alter many treatment parameters during stimulation operations. Moreover, in unconventional shale reservoir stimulation, the main goal is to maximize the stimulated reservoir volume to maximize the hydraulically connected (open) fractures in the formation matrix. This allows the hydrocarbons stored inside the impermeable pore space to be produced. In EGS, the main goal is fracture connectivity between wells, allowing water to flow from the injection well to the production well as it heats up and recovers thermal energy from the formation.

We review the feasibility of and strategies for applying completion techniques like those used in shale gas — such as multi-stage "plug-and-perforate” and "packer-and-port" completions —in horizontal EGS wells. The scope of our study is to determine various techniques used in the petroleum recovery industry that can be applied to an EGS, focusing especially on the fracture construction and completion of the EGS production well. A previous report (Olson et al., 2015) covers specific details on general design of an EGS system in light of oil and gas unconventional resource development and the design and completion of an injector well.

The transferable techniques include, but are not limited to, currently available products, methods of stimulation, reservoir modeling, and reservoir condition monitoring. Our project is a collaboration between the National Renewable Energy Laboratory (NREL) and the Colorado School of Mines (CSM).

\section{Gas and Oil Technologies Applicable to Geothermal Setting}

As noted in the previous report (Olson et al., 2015), most of the transferable technology from the oil industry to an EGS comes from steam-assisted gravity drainage (SAGD) and high-pressure high-temperature (HPHT) wells, and especially from unconventional shale plays. The development of these techniques has driven high-temperature completion technology.

As an example, SAGD technology is like an EGS system in reverse (see Figure 1). A SAGD system uses two horizontal wellbores in which the upper wellbore is used to inject heat via steam, while the lower wellbore collects the reduced-viscosity heavy oil. The operational temperatures for SAGD are similar to the temperatures desired for an EGS (around $500^{\circ} \mathrm{F}$ ). The components used in a SAGD system often include open-hole sliding-sleeve systems with external packers like the "packer-and-port" completion technique explored in this project. HPHT wells encountered in today's deep wells range up to $20,000 \mathrm{psi}$ and over $500^{\circ} \mathrm{F}$. These conditions 
have pushed the technology of plugs and stimulation equipment and have led to modified techniques developed to overcome pressure- and temperature-related problems.

Unconventional shale plays often use long horizontal wells requiring multiple, individually isolated zones (called "stages") for stimulation. Hydraulic fracturing on a horizontal plane has the benefit of using the in-situ stress fields of the rock to assist in fracture propagation. The direction of the horizontal wellbore must be oriented in the direction of the highest horizontal stress to ensure that the induced fractures are perpendicular to the wellbore. These fractures will then be parallel to each other, enhancing hydrocarbon recovery between fractures. Multi-stage fracturing is used in many wells today drilled in the United States; coupled with horizontal drilling, it is the primary technology enabler for the "shale revolution."

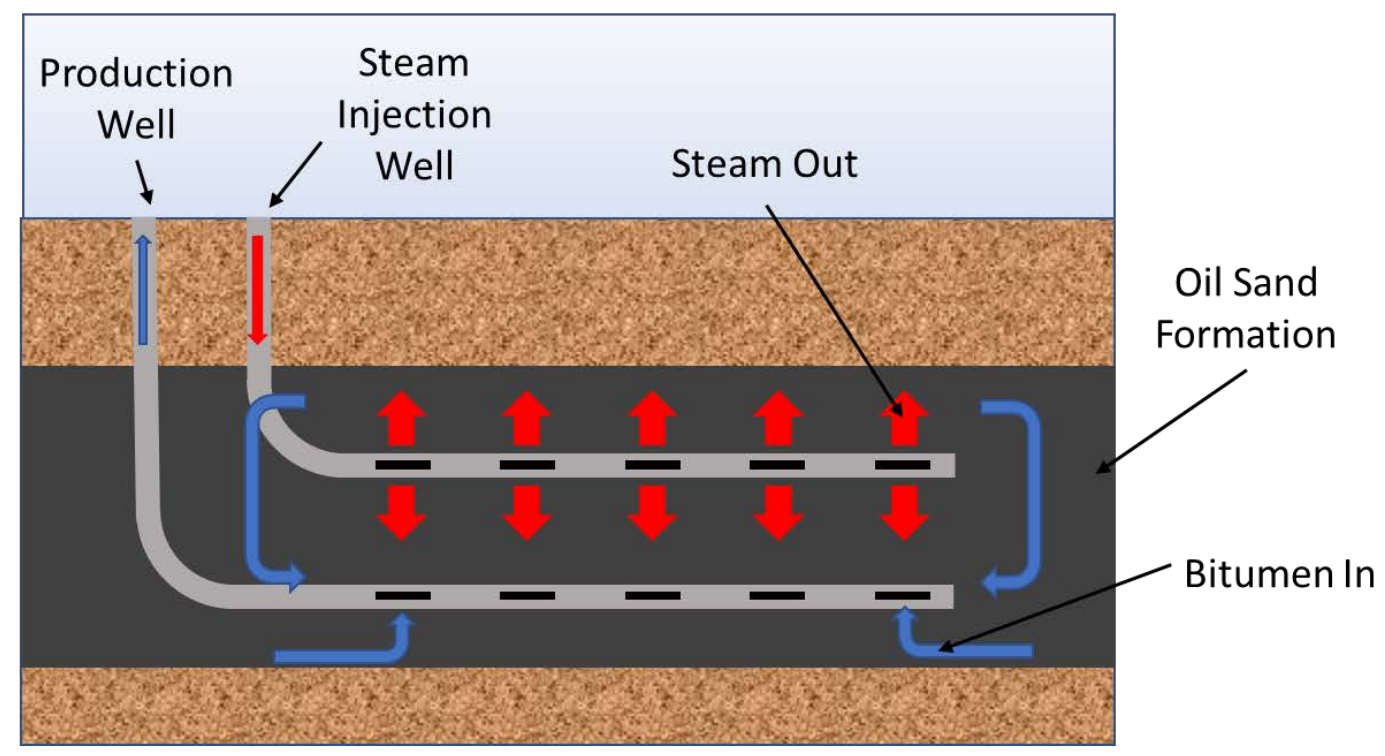

Figure 1. Diagram of a steam-assisted gravity drainage (SAGD) system.

\section{Focus of this Study}

Our study focuses on the completion of a horizontal well in the system similar to the SAGD systems described above (Figure 1). The goal of the completion of the horizontal well is to create multiple, hydraulically isolated (i.e., independent, non-intersecting) fracture zones within the horizontal section of the well. We explore the ability to use or adapt techniques and technology from the oil and gas industry to achieve this goal.

We first establish the requirements for the horizontal completion in the context of the overall EGS requirements (e.g., temperature, flow rates, number of fractures, fracture spacing, pressures). Next, we propose a wellbore design that can meet these requirements. Finally, we discuss completion stimulation techniques and technologies from the oil and gas industry and evaluate their applicability to an EGS setting. 


\section{Objectives of this Study}

Our study has the following objectives:

- Determine how petroleum technologies and techniques can be adapted and applied to completing horizontal geothermal wells with multistage hydraulic stimulations, with a focus on well-completion techniques. The assumption is that a horizontal well is already drilled (Polsky et al., 2008).

- Determine the ability to isolate a zone, access the formation, and deliver fluids at a pressure and flow rate to hydraulically stimulate the formation in a geothermal setting.

- Move EGS development toward a “manufacturing” framework like unconventional oil and gas recovery.

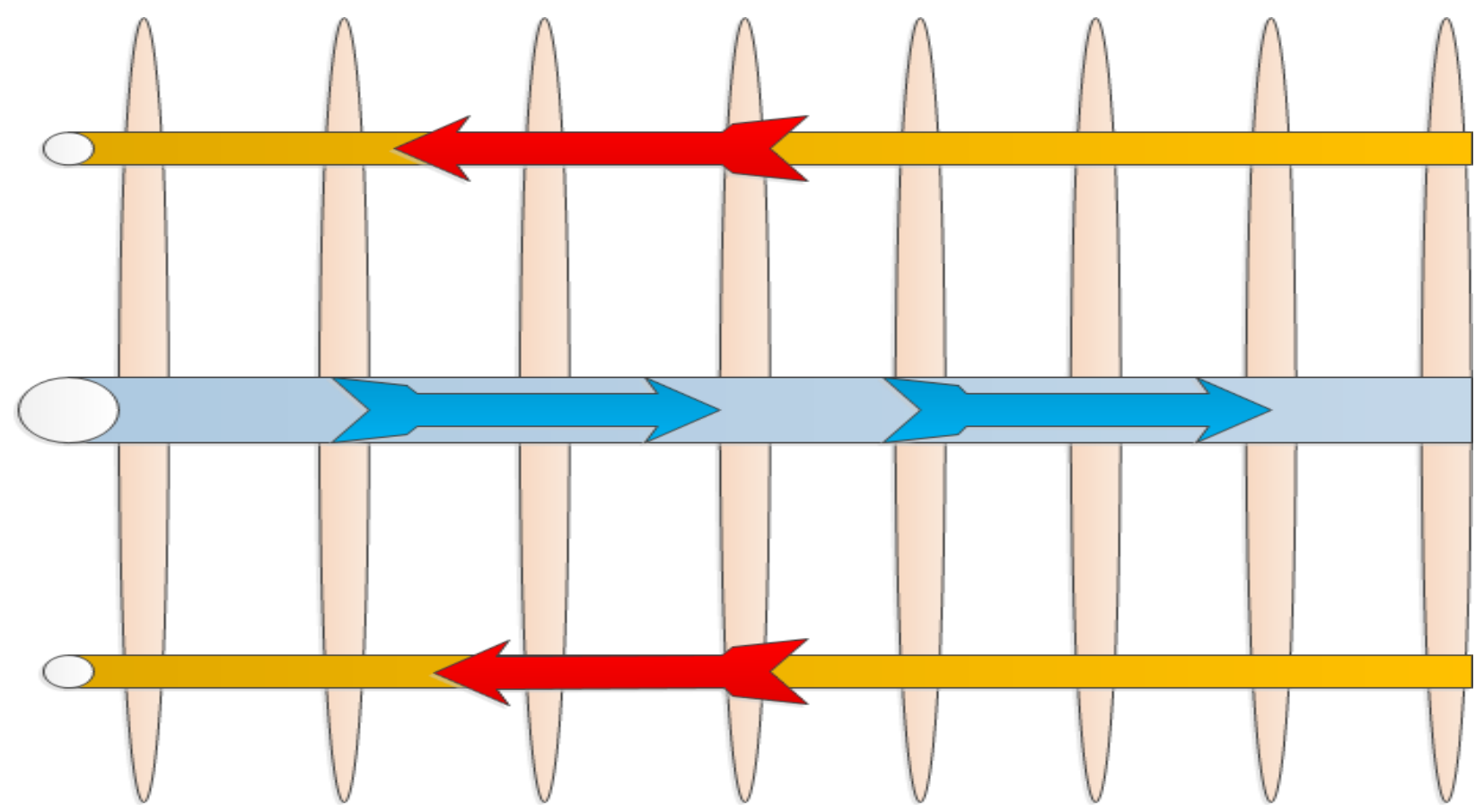

Figure 2. Generalized top-down look at the proposed EGS system. Red arrows show production wells and blue arrows show the injection well.

\section{Conceptual Model of the EGS}

The EGS proposed in the previous and current report is a set of horizontal wells intersecting multiple vertical fractures. The conceptual model for the proposed EGS system is shown in Figure 2. The proposed horizontal EGS will use one injector well and multiple production wells to achieve a system capable of producing 5 megawatts of electricity ( $\mathrm{MW}_{\mathrm{e}}$ ) gross per production well. This is a typical per-well generation capacity in the hydrothermal industry and is a good benchmark for an EGS project that should be commercially feasible in today's market. The amount of heated fluid necessary to generate $5 \mathrm{MW}$ (gross) is around 50,000 barrels per day (bpd) ( $\sim 80 \mathrm{~kg} / \mathrm{s})$ depending on the production well temperature. Another consideration is that the intended longevity of the suggested hot dry rock (HDR) EGS is 20-30 years. To achieve the prospective flow rates over this time frame, the size of the reservoir must be considerably larger than that observed in previous EGS projects. The size of the reservoir can be increased by creating more induced fracture networks. A horizontal system provides the opportunity to 
hydraulically fracture numerous stages, resulting in a reservoir that can support the prospective flows without sacrificing reservoir integrity.

At this time, we propose that the injection well be drilled first, followed by the two production wells. The orientation of the three wells is parallel and at the same depth. (We have not yet determined the specific depth and whether this configuration is the optimal placement.) Once the wells are prepared, reservoir stimulation is performed through the injection well. The plan is to use a sufficiently large stimulation to intersect the other two wells. The two production wells would open and have as low a bottom hole pressure as practical. This condition can potentially induce a "frac hit" (as it is called in the oil and gas industry), which is the connection between the injector well and the producing wells ${ }^{1}$.

The azimuth of the horizontal section will be in the direction of minimum principal stress of the formation to create transverse fractures in relation to the wellbore. This orientation minimizes the distance the fracture must travel to intersect the production wells. The stimulation of the reservoir's fracture network is modeled using Schlumberger's Mangrove hydraulic fracturing software, which is described in detail later in this report.

The fracture network will be mapped (e.g., micro-seismically) to characterize the connectivity to the production wells. The placement of the producing wells is integral to the efficiency of the system. Their placement will depend on the location of the injection well, the potential intersection of as many fractures as possible, and the distance the fluid must travel through the reservoir before being produced. The connectivity of the wells establishes the flow rates achievable from the system for a given pressure drive, whereas the distance that the fluid travels through the reservoir determines the amount of useful heat that can be extracted from the rock by the fluid over the reservoir lifetime.

Keys to accomplishing this model are:

- Completing the horizontal wells to control location and spacing of fractures.

- Starting with a central horizontal injection well and two horizontal wing production wells.

- Being able to isolate zones for stimulation and production.

- Stimulating fractures by staging into the isolated zones.

- Injecting fluid and flow through fractures from the injection well to the production wells and producing hot fluids at the required rates.

- Monitoring (and controlling) the fluid flow and temperature for as long as possible without undue maintenance requirements.

Questions to answer in this study are the following:

\footnotetext{
${ }^{1}$ This methodology assumes that the stress state is well known and the direction of fracture growth can be predicted with confidence. A more conservative and conventional proposed approach is to drill in injection well, stimulate and "watch" (via micro-seismic monitors, for example) where fracturing occurs, and then drill the production well(s) into the fracture cloud, or the location where fractures are suspected to be.
} 
- What does the fracture network look like (e.g., number of fractures, fracture lengths, fracture aperture)?

- What is needed to create these fractures (e.g., flow rate, fluid properties, and pressure during stimulation)?

- Where do the fractures go and what is their geometry? How do potential tectonic stresses affect the geometry? How does a discrete fracture network impact the fracture construction? 


\section{Enhanced Geothermal System Requirements and Modeling}

The completion design of both the injection and production wells depends on the performance requirements for the entire system. The performance of the reservoir is the key component to be considered and is determined via the following: induced fracture network, flow rates through the reservoir, temperature of fluids into and out of the reservoir, spacing of fracture networks, and size of fractures. The creation or stimulation of fracture networks will have a major effect on the performance of the system overall.

\section{Completion Requirements and Assumptions}

In the previous report, the completion of the injection well was designed around the requirements of the system; that section is repeated here. Each system will be unique to the specific reservoir characteristics. The specific requirements for each EGS will vary from site to site. The depth, initial temperature, and extent of the reservoir must be considered in determining a completion design. For this study, we made the following initial assumptions:

- Reservoir Temperature: $200^{\circ} \mathrm{C}\left(392^{\circ} \mathrm{F}\right)$

- Reinjection Temperature: $75^{\circ} \mathrm{C}\left(167^{\circ} \mathrm{F}\right)$

- Production Well Flow Rate: 80 kg/s (43,500 bpd)

- Injection Well Flow Rate: 160 kg/s (87,000 bpd)

- Power Output per Production Well (approx.): $5.5 \mathrm{MW}_{\mathrm{e}}$

The pressure requirements for the completion design depend on the well depth (which determines the hydrostatic and friction pressures), pressure required for stimulation, and pressure during operation (hydrostatic injection pump exit pressure). The stimulation schedule to induce the fractures will most likely be the highest amount of stress exerted on the design. The high flow rates and abrasive fluids associated with hydraulic fracturing can be damaging to the completion components. The design should assume that the well will require a workover at some point in the future.

The number of stages that will be hydraulically fractured and the lifespan of the system will also have to be considered. The number of stages required from the completion depends on many variables, including the performance of the fracture network from each zone, total flow through each zone, and expected lifetime of the reservoir. Gringarten et al. (1975) proposed a mathematical model of the effectiveness and longevity of a multi-fracture HDR EGS. This model, hereafter referred to as the Gringarten model, compares the production well temperature from the EGS reservoir with the produced flow rates, the initial temperature of the reservoir, the intended lifespan of the system, the fracture spacing, and the total fracture surface area. The Gringarten model assumes that the EGS reservoir is composed of "an infinite number of parallel, equidistant, vertical fractures of uniform thickness, separated by blocks of homogeneous and isotropic, impermeable rock..." (Gringarten, et al., 1975). The model admittedly has some "simplifying assumptions" (Gringarten, et al., 1975), but it provides an analytic solution to an idealized "best case" scenario for an engineered fracture network that provides insights into the fracture areas required to support a given flow rate over the course of decades. A full analysis of 
the Gringarten model is outlined in Gringarten's publication Theory of Heat Extraction from Fractured Hot Dry Rock (1975), and we discuss a basic analysis of the model here.

The limitations to the accuracy of the model are mostly confined to the fracture network. The model assumes no leak off into formation and uniform fracture length, height, and aperture. The model also assumes that the reservoir resides in a homogenous formation. Although these limitations are not realistic, the limiting assumptions will always vary from one system to another; hence, the generalized model is still applicable.

We applied the Gringarten model to the system being modeled for our study to determine the number of fracture stages required and the size of the fractures. The assumptions made were a $200^{\circ} \mathrm{C}\left(392^{\circ} \mathrm{F}\right)$ initial reservoir temperature, a $175^{\circ} \mathrm{C}\left(347^{\circ} \mathrm{F}\right)$ final production well temperature, a 30-year lifespan, a total flow rate of 43,500 bpd $(80 \mathrm{~kg} / \mathrm{s})$, a fracture height of 984 feet $(300 \mathrm{~m})$, and a maximum fracture length of 3,480 feet $(1,060 \mathrm{~m})$. To realize the $\sim 5 \mathrm{MWe}$ net power output, the following results were found to be necessary: a minimum of 12 fractures must be induced, a flow rate of $80 \mathrm{~kg} / \mathrm{s}$, a fracture spacing of 200 feet $(60 \mathrm{~m})$, and an overall fracture surface area of $41 \times 10^{8} \mathrm{ft}^{2}\left(3.8 \mathrm{~km}^{2}\right)$. The spacing of fractures can be controlled by the spacing of perforations in the horizontal leg of the well.

\section{Summary of EGS and Well Assumptions and Requirements}

Below is a summary of the assumptions used and performance requirements for the injection well completion design.

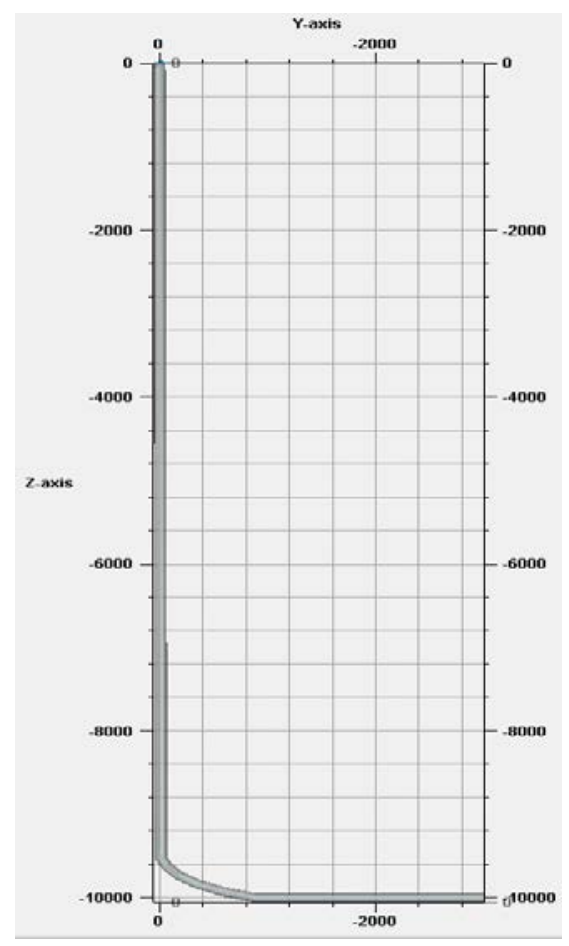

Figure 3. Vertical section of proposed wellbore trajectory. 
- Well Configuration

o Central horizontal injection well, oriented perpendicular to minimum principal stress

o Two horizontal production wells, oriented parallel to injection well and flanking each side of it, and located up to 3,000 feet $( \pm 1 \mathrm{~km})$ from injection well (fracture length)

o Wellbore trajectory shown in Figure 3 and Figure 4

- Reservoir Properties

o Reservoir temperature: $200^{\circ} \mathrm{C}\left(392^{\circ} \mathrm{F}\right)$

o Lithology: based on Newberry 55-29 well logs

o Target depth: 3,050 m (10,000 ft)

- Hydraulic Stimulation

O Number of fractures: 12

O Fracture spacing: $200 \mathrm{ft}(60 \mathrm{~m})$

0 Fracture length: $3,500 \mathrm{ft}(1,000 \mathrm{~m})$

O Fracture height: $984 \mathrm{ft}$ (300 m) 


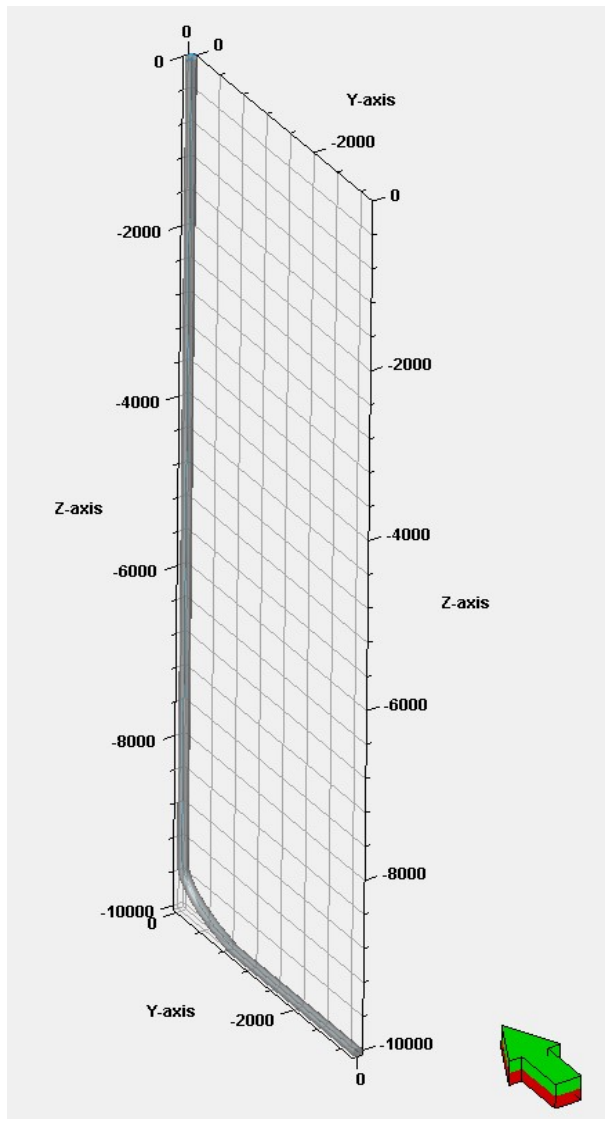

Figure 4. Isometric view of proposed wellbore trajectory.

Enhanced geothermal systems require higher flow rates than their oil and gas counterparts due to the energy content of the extracted fluids. This will result in a larger inner diameter (ID) of tubing or liners, larger and potentially higher-strength casing designs (due to thermal cycling), higher risk of scaling and corrosive deterioration, and larger pumps. An EGS well requires an approximate lifespan of 30 years to match the expected lifetime of the surface power plant.

\section{Wellbore Construction}

The drilling process for the injection and production wells above and within the horizontal section will be identical for the wells, except for the wellbore size. The production wells—noting the lower production flowrates as compared to the injection well—could be reduced in borehole, casing, and tubing size. This size reduction also reduces the cost; however, it takes away flexibility should the need arise to rearrange the well injection location.

\section{Injection Well Specifications}

- Injection Well Operation

O Injection well flow rate: $160 \mathrm{~kg} / \mathrm{s}(87,000 \mathrm{bpd})$

o Re-injection temperature: $75^{\circ} \mathrm{C}\left(167^{\circ} \mathrm{F}\right)$

- Injection Well Design 
o Lateral length: $915 \mathrm{~m} \mathrm{(3,000 \textrm {ft } )}$

o Vertical-to-horizontal turn rate: $10 \% 100 \mathrm{ft}$

o Need casing to allow control of stimulation and injection fluid

- Open hole does not allow for this engineering control

o Burst Pressure

- Stimulation operation pressures will likely dominate this issue

- Water Injection model does not show a high loading through the friction through pipe and perforations. However, the injection pressure through the fractures to the producers is not known and could be significant enough to affect the casing design.

o Collapse Resistance

- This is not considered a significant effect, assuming the casing is not unloaded and empty at any time.

\section{Production Well Specifications}

- Production Well Operation

o Production well flow rate: $80 \mathrm{~kg} / \mathrm{s}$ (43,500 bpd)

o Production temperature: $200^{\circ} \mathrm{C}\left(397^{\circ} \mathrm{F}\right)$

- Production Well Design

o Production well design should control fluid flow rates into the wellbore

o Burst Pressure

- This is not considered a significant effect because the goal is to get as low of a bottom-hole pressure for production inflow performance as possible

o Collapse Resistance

- This may be an issue if bottom-hole pressures becomes too low from artificial-lift operations

_ Artificial lift will need to be accommodated

- Corrosion will likely be a problem. It is unknown if any corrosion gases would be assimilated in the production fluid as it travels from the injector to the producer. Corrosion damage potential could be significantly high.

_ Scale could be an issue

- Tubing will protect vertical casing string

_ "Jewelry" in the horizontal section will likely require corrosion-resistant alloy (CRA) such as Inconel ${ }^{\circledR}$, Incoloy ${ }^{\circledR}$, and Hasteloy ${ }^{\circledR}$

- In general, it is expected that the production well would be drilled and generally similar to the injection well

o Types of horizontal section completion in production wells 
- Open hole (can collapse and has no flow control)

- Cemented and perforated (some fluid control)

- Sliding sleeves (if functional, can control flow)

_ Intelligent sliding sleeve (fluid control, but lifetime limited)

\section{Casing Design}

To achieve a well's longevity of 30 years, a robust casing design will be necessary. The casing used in a HDR EGS well will require corrosion resistance, temperature-cycling stability, longterm exposure to high temperatures, and a high burst and collapse strength. The casing design for the proposed central injection well is critical to the success of the EGS system. The casing must have the following properties:

- Largest bore consistent with the production pressure and rate needed for the EGS system

- Able to withstand the highest anticipated fracture stimulation pressure and rates if needed

- Able to handle the high-temperature conditions without burst, collapse, and tensile failure

- The cycling between the high- and low-temperature conditions, especially regarding axial stress

- Casing connections that are leak-tight even under varying temperature conditions

- Casing connections that exceed the tensile strength needed for thermal cycling

- Corrosion resistant to any expected constituents such as $\mathrm{CO}_{2}$ or $\mathrm{H}_{2} \mathrm{~S}$.

Scale could be an issue because the injection fluid could pick up scaling products as it cycles through the fractures. $\mathrm{CO}_{2}$ or $\mathrm{H}_{2} \mathrm{~S}$ might also be expected in the production stream; but this has yet to be proven. Erosion from production is not likely because the casing is expected to have many ports for production, making the individual perforation or port flows relatively low.

The design of this string would be similar to a typical geothermal well, where the temperature rises and remains high during production. The casing is anticipated to heat up to geothermal conditions after running and either cementing in place or the setting of external packers. However, any fluid circulation for cleanout or other workover operations may cause the wellbore to cool down. Given the complexity of the thermal cycling of the well, we recommend that the casing be designed to handle any thermal condition from $20^{\circ} \mathrm{C}$ (about ambient-temperature injection water) to the geothermal condition, which we assume in this project to be $200^{\circ} \mathrm{C}$. 
The design of the production casing is based on 50,000 bbls per day production. This means that a smaller-diameter casing string could be used. A 7”, 7-5/8”, or 8-5/8” diameter could work. However, artificial lift is likely, so a large electric submersible pump (ESP), for example, will be required. The review of artificial lift systems was not part of our study; however, for this report, 9-5/8” casing was used because that gives room for a large ESP and dimensional compatibility with the injector. Table 1 shows some example casing strings and their performance properties.

Table 1. Suggested casing strings

\begin{tabular}{|c|c|c|c|c|c|c|c|}
\hline $\begin{array}{l}\bar{\Xi} \\
\frac{\Xi}{0} \\
0\end{array}$ & 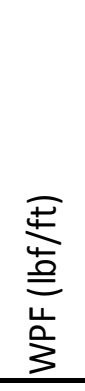 & $\begin{array}{l}\frac{0}{0} \\
\frac{\pi}{0} \\
\end{array}$ & $\begin{array}{l}\stackrel{\Xi}{\subseteq} \\
\subseteq\end{array}$ & 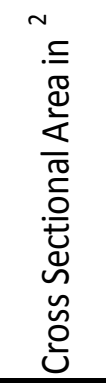 & 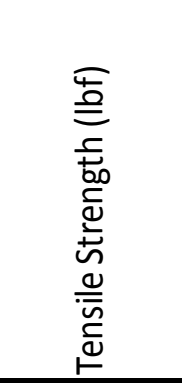 & 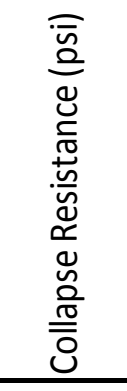 & 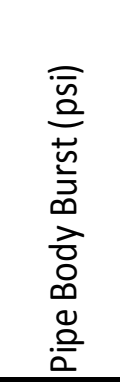 \\
\hline 7 & 35.0 & P110 & 6.004 & 10.17 & $1,119,000$ & 13,030 & 13,700 \\
\hline 7.625 & 39.0 & P110 & 6.625 & 11.19 & $1,231,000$ & 11,080 & 12,620 \\
\hline 8.625 & 49.0 & P110 & 7.511 & 14.12 & $1,553,000$ & 10,730 & 12,430 \\
\hline 9.625 & 53.5 & P110 & 8.535 & 15.55 & $1,710,000$ & 7,950 & 10,900 \\
\hline
\end{tabular}

Given the large tensile loads, a high-grade casing string is desired. A P110 grade is common and is often used in horizontal sections of shale development wells in petroleum operations. We use it here because of the potential for high fracture stimulation pressures and axial loads due to thermal cycling. The casing we consider in this report is suggested to be identical to the injection well, which is a 9-5/8” 53.5 ppf P110. This does not preclude any other design, and if these wells are developed, a more thorough casing-string design using local data inputs must be done.

\section{Material Properties}

The material and hence performance properties are affected by elevated temperatures. In typical petroleum operations, the steel property changes are considered fixed, so this is usually ignored. From the previous report, sufficient data indicate that the magnitude of the steel material properties changes with temperature. The yield point, coefficient of thermal expansion, and modulus of elasticity are all affected. In addition, the hardness and toughness of the steel are also affected. The temperature effect on hardness depends on the alloying agents in the steel. The toughness climbs from more brittle behavior to more ductile behavior as temperature climbs, leading to potential creep issues. This phenomenon becomes dominant at elevated temperatures, especially when temperature exceeds half of the melting point, which should not be an issue in this proposed EGS system. Yield strength and modulus of elasticity have the highest importance in conventional design methods.

\section{Yield Point}

The yield point of a metal is considered the point at which the material no longer acts elastically to an applied stress. This situation can be thought of as the crystals within the structure of the metal now starting to slide past one another along the crystal boundaries. The metal, on the 
release of the applied stress, no longer returns to the original dimensions but instead has a permanent change in dimension-a plastic deformation. The hotter the metal, the lower the transition from elastic to plastic behavior (Figure 5). Given that the yield strength is a factor in the burst, collapse, and tensile strengths, those also drop. This change in yield point has been measured in laboratories. In general, steel loses about $0.03 \%$ of its yield strength above $68^{\circ} \mathrm{F}$ $\left(20^{\circ} \mathrm{C}\right)$.

For corrosion-resistant alloys (CRA), the temperature effect on yield point can be significant (Figure 6). Duplex stainless steels are affected strongly. Before using a CRA, the material should be vetted through elevated temperature testing.

$$
Y P_{\text {adjusted }}=Y P_{68^{\circ} F}\left(1-0.0003\left[T-68^{\circ} F\right]\right)
$$

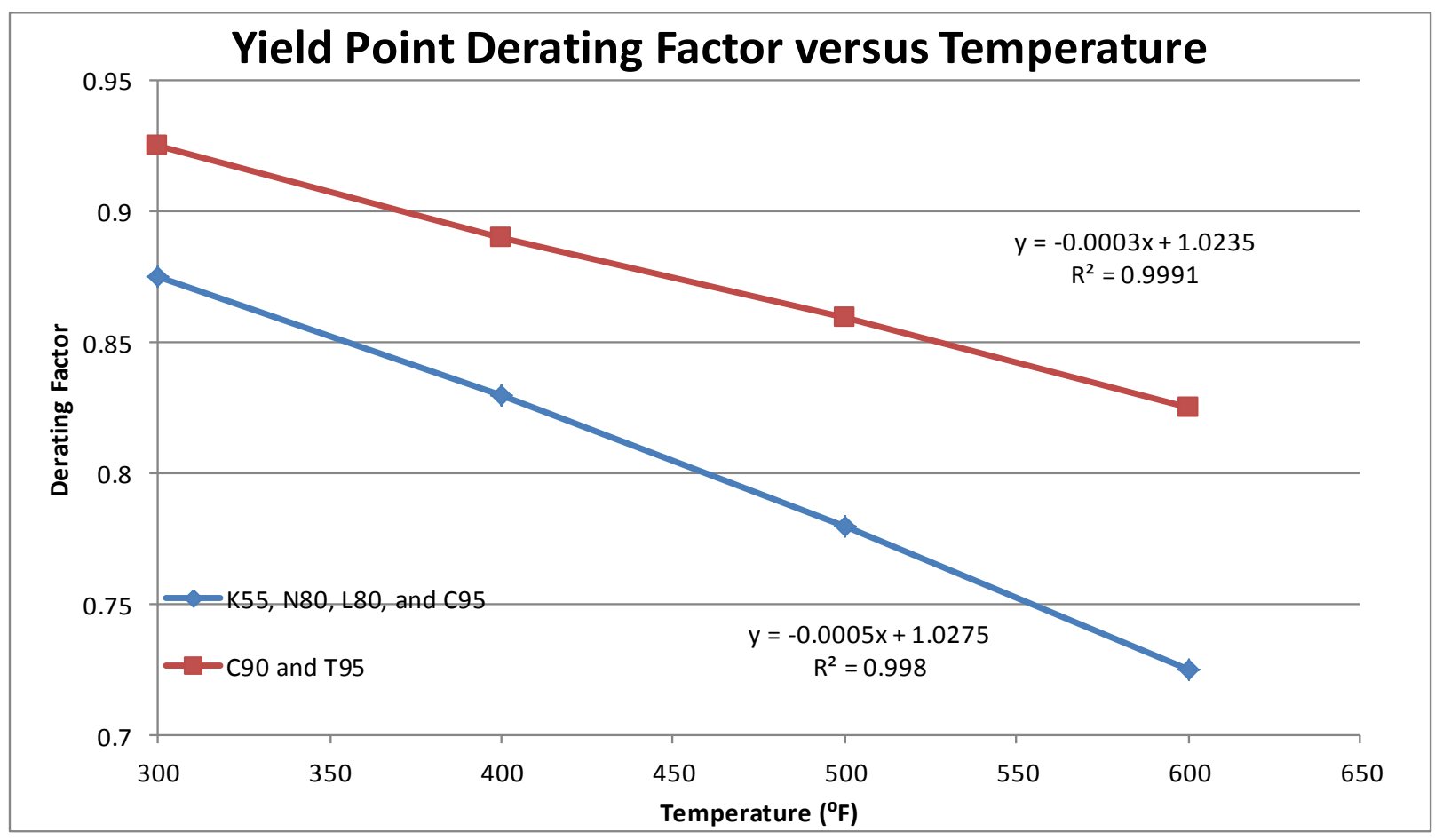

Figure 5. Yield point derating factor versus temperature.

\section{Modulus of Elasticity}

The modulus of elasticity, E, sometimes called Young's Modulus, is the slope of the function of stress versus strain within the elastic limit on a stress/strain diagram (Figure 7). It is commonly set at 30,000,000 psi for steel; however, it varies with temperature. For the range of temperatures expected with this proposed EGS system, the E value will vary from 30,000,000 psi to just under $29,000,000$ psi. This will have a minor effect on the strength of the steel in burst and collapse; however, it does affect the thermal stress loading.

\section{Coefficient of Thermal Expansion}

The coefficient of thermal expansion is the measure of how a material changes dimensions with a temperature change. With steel, this is often considered a constant. The value is frequently set 
to $6.9 \times 10^{-6}$ per ${ }^{\circ} \mathrm{F}$, which is roughly what it is at $145^{\circ} \mathrm{F}$. However, as Figure 7 shows, the thermal expansion coefficient does vary with temperature and this should be considered when large temperature variations are expected.

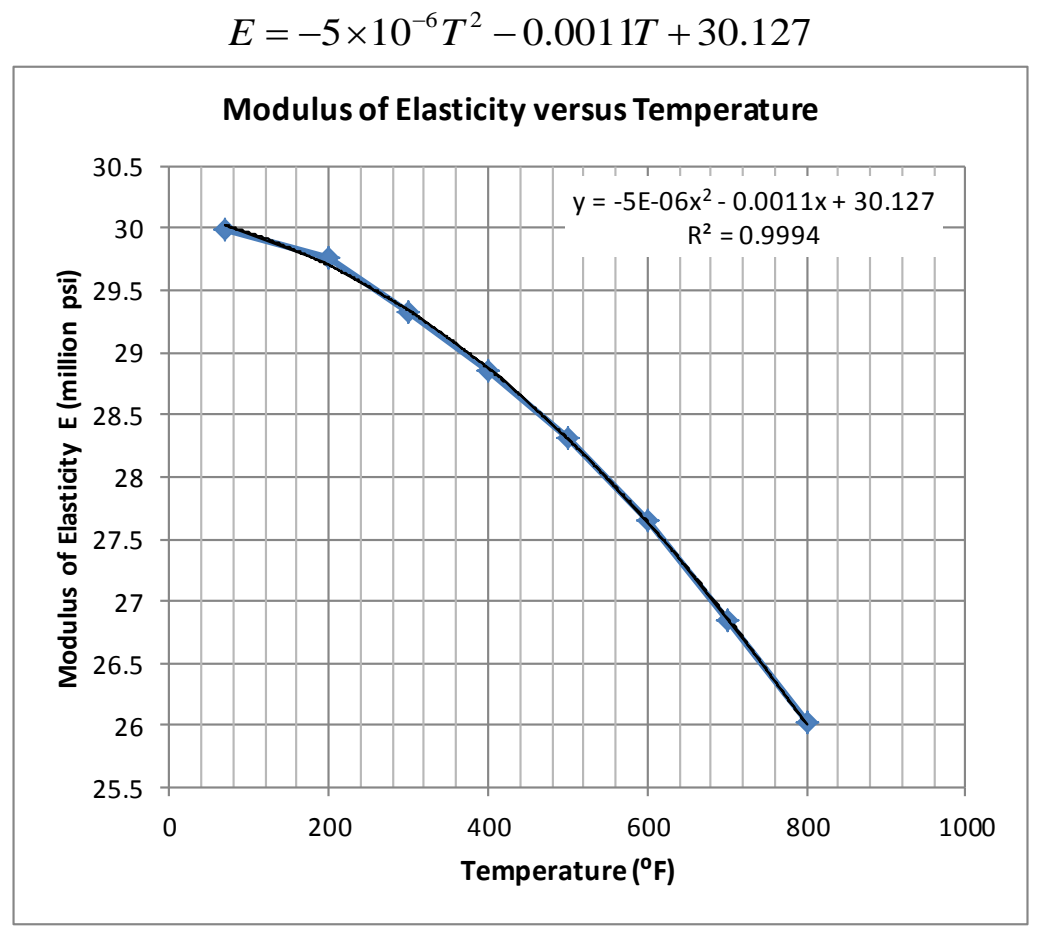

Figure 6. Modulus of elasticity versus temperature.

$$
\alpha=-3 \times 10^{-6} T^{2}+0.0065 T+6.0183
$$

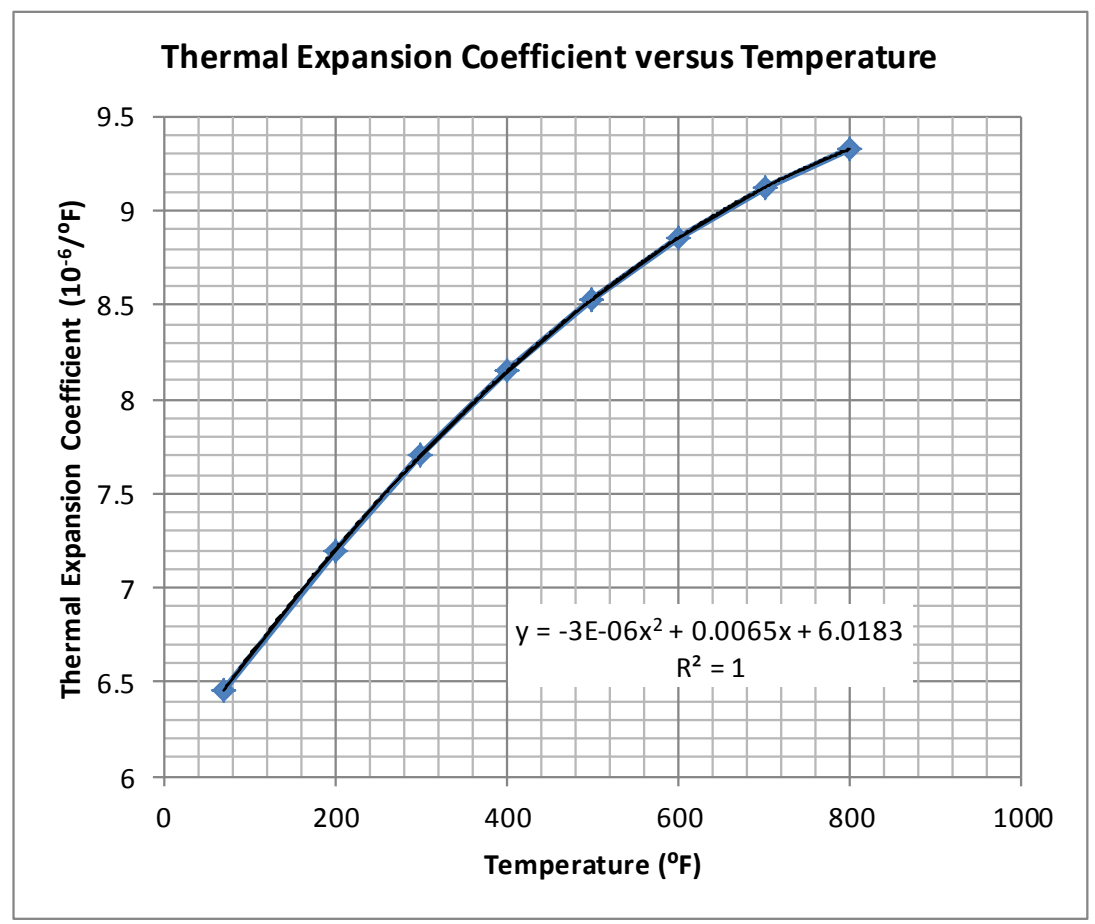

Figure 7. Thermal expansion coefficient versus temperature. 


\section{Casing under Thermal Cycling Conditions}

If we assume that the casing is cemented or packers are set at the lowest temperature, then the casing will be locked in place. Then, upon cessation of injection fluid, the casing will expand on heating to geothermal conditions. Given that it will be constrained either by cement or external packers, upon heating, the expansion forces will be considerable. Using the coefficient of thermal expansion times the modulus of elasticity for a given temperature gives a value of psi for every degree Fahrenheit change. The thermally induced stress between the higher temperature and $70^{\circ} \mathrm{F}$ can be determined by multiplying the change in temperature by that previous value. Then using the cross-sectional area (assumed to be constant because it is nearly constant) multiplied by the thermal stress gives the thermal force over that temperature change.

$$
\sigma=E \alpha \Delta T
$$

Using the modulus of elasticity to determine the yield strength at a given temperature multiplied by the cross-sectional area gives a tensile strength at that temperature (rounded to the nearest $1,000 \mathrm{lbf}$ as per API standards). Steel is assumed to be homogenous and isotropic. Comparing the thermal force to the tensile strength gives a design factor. A design factor of less than 1 indicates that the casing has gone beyond its yield point and is thermally yielded (plastic deformation). If thermal stress exceeds yield strength of casing, hot yielding occurs. Note that the casing could still be functioning normally, and it most likely is; however, the casing state is beyond its elastic limit.

If the stress from hot yielding continues to increase, the stress does not rise above the yield point; instead, its compressive stress maintains a constant state while the casing, in effect, shortens. This shortening does not really occur; however, because it should have expanded but could not, the casing is, in effect, shorter than it should be. This is the plastic deformation that occurs. The casing upon cooling will be shorter than it was originally, leading to tension stress. What this does to the casing is that, upon cooling, it will not be in a stress-free state. Plastic deformation will leave a residual stress upon cooling.

This can be shown as follows. The temperature at which 9-5/8” 53.5 ppf P110 starts to yield is $470^{\circ} \mathrm{F}$, as shown at the crossover in Figure 8. This point is below the proposed temperature of the EGS system, so the proposed system is satisfactory under these conditions. However, for the sake of discussion, let us say that the temperature went to $600^{\circ} \mathrm{F}$. The yield point of $96,734 \mathrm{psi}$ at that yield temperature gives the temperature where axial stress is zero upon cooling. The value of $\mathrm{E} \alpha$ at that temperature is $239.75 \mathrm{psi} /{ }^{\circ} \mathrm{F}$. Therefore, the temperature for zero axial stress would be:

$$
T=600-\frac{96,734}{239.74}=196.5^{\circ} \mathrm{F} .
$$

Continuing the temperature drop to $68^{\circ} \mathrm{F}$ would induce a tension stress of:

$$
\sigma=239.74(196.5-68)=30,800 \mathrm{psi} .
$$

This value is well within the capability of the casing string. Of course, these values are temperature dependent, yet they are assumed constant here. This approach is more conservative because the stress rate drops with temperature, leading to lower values. 


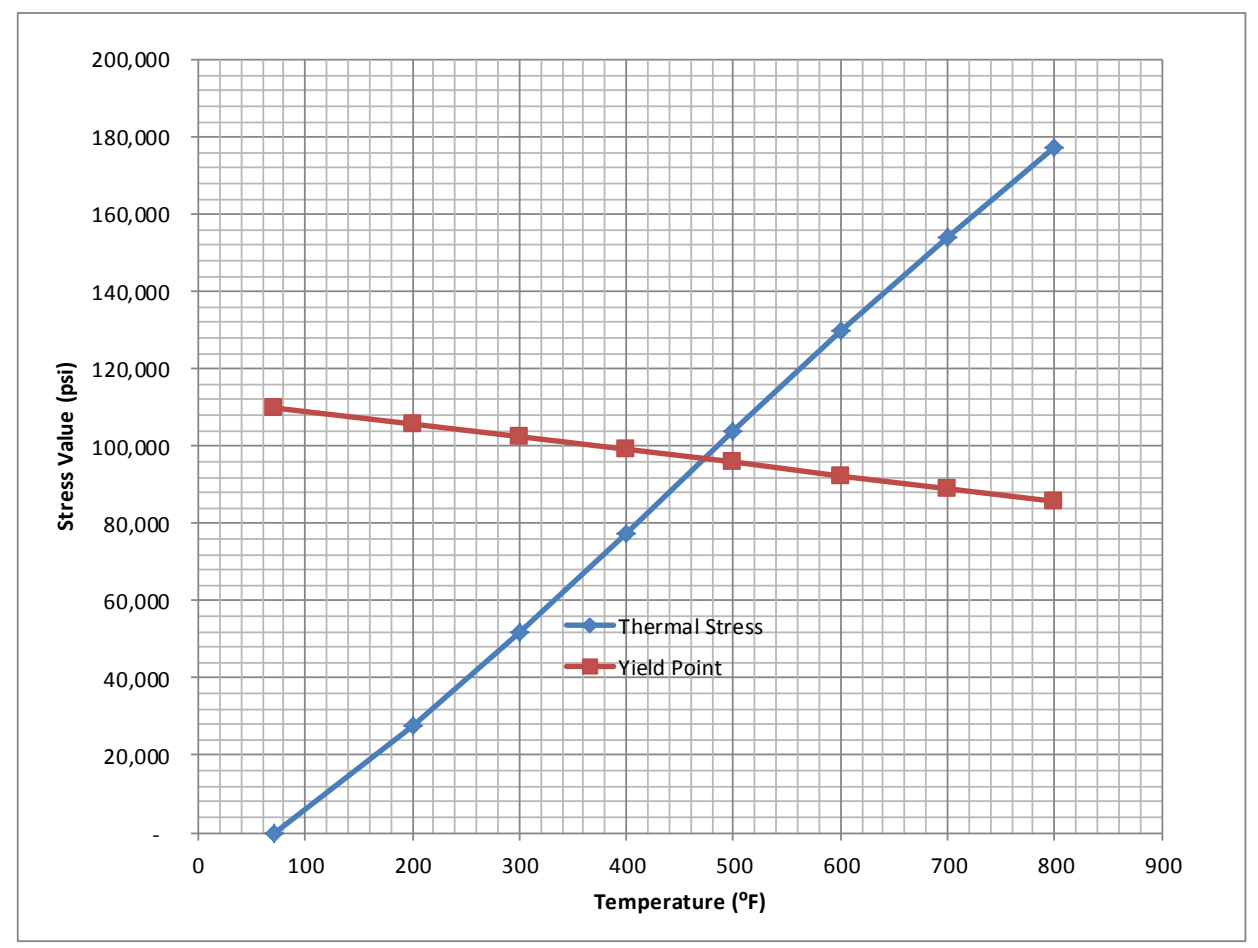

Figure 8. Stress value versus temperature.

The good news is that the horizontal section of the casing will be very close to zero axial load because it is laying on the low side of the hole. All of the tensile strength can be used to resist the thermal stress loads. Some induced axial loads due to stimulation or injection fluid friction need to be analyzed.

\section{Burst and Collapse Pressures}

For burst, the largest likely loads are during cementing or any stimulation. The burst rating for the casing is near 11,000 psi for the lowest value in Table 1. For collapse, the situation is different. In general, collapse ratings are lower than their burst ratings. Because the goal is to pull the production well bottom-hole pressures to low values, collapse loading will be high. However, because this load will likely be in the horizontal section, the axial loading from gravity is low; but, the axial loading from temperature cycling could be large. If casing is in tension, the collapse rating will be reduced further. It is likely, however, that the casing would be in compression, which slightly increases the collapse rating. But with residual yielding stresses from thermal cycling, the collapse resistance will be reduced. This very complex issue will need detailed, specific analysis with locally expected conditions.

\section{Casing Connections or Couplers}

Another issue to consider in well design is the casing connections. The casing couplers require special attention in a geothermal well. The couplings and pins of the standard API-type connections (STC, LTC, and BTC) are actually designed for tension loading. Compression loading is not common. A case study was presented (Brunetti and Mezzeti, 1970) where 86\% of total casing failures occurred at the couplings (Teodoriu, et al., 2008). An API Buttress connection is the most common coupling used today in geothermal wells. However, current technologies in "Premium" couplings are making them more viable for HDR applications albeit 
at a higher cost. In deep horizontal wells, the couplings, as well as the casing, will undergo extreme axial, compressive, and bending stresses. The bending stresses can be lessened with a wellbore designed with a larger radius of curvature (Nurmi, 1995). Additionally, temperature cycling of the casing can cause failure due to thermally induced fatigue. Fatigue does not always imply failure, but cyclic cooling and heating exposes the casing string to cyclic tensioncompression loading that may lead to casing failure (Teodoriu, et al., 2008). Material properties such as the yield strength change with temperature, which implies that at elevated temperatures the resistance of a casing is lower than at ambient temperature (Teodoriu, et al., 2008). These stresses will be concentrated in couplings due to the geometry of the design, which means that special attention should be given to the connections when evaluating cyclic fatigue, especially at the first threads of the casing. A non-API Premium connection should be considered.

\section{Finite-Element Modeling of Axial Loading of Proposed Casing Designs}

To confirm the results of the closed-form casing design solutions, we created and tested a simple finite-element model to determine the temperature-cycling stress effects. A commercial software package, ANSYS (versions 15.0 and 16.2), was used to model the injection-well casing design. The model was based on an axisymmetric 1-dimensional structure of half of a joint of 9-5/8" P110 53.5\# casing fully cemented with API Class “G” neat inside a 12-1/4” hole (see Figure 9). The model's initial temperature conditions were $20^{\circ} \mathrm{C}$, at which the well was "locked down" with cement. The model then was heated to $200^{\circ} \mathrm{C}$, which was thought to be a worst-case scenario. The steel properties used in the model were experimentally determined by a major casing manufacturer (SM110T, Nippon Steel \& Sumitomo Metal Corp).

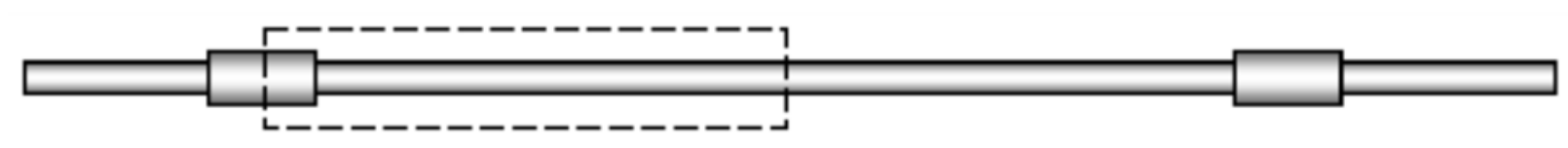

Figure 9. Model of 9-5/8" casing is in the dotted-box section. The rest of the casing is assumed to be symmetric.

The goal of our analysis was to examine worst-case scenarios, so the initial temperature was assumed to start at $20^{\circ} \mathrm{C}$ and rise to a maximum temperature of $200^{\circ} \mathrm{C}$. The initial condition assumed that the cement actually set at $20^{\circ} \mathrm{C}$-again, this is worst-case scenario.

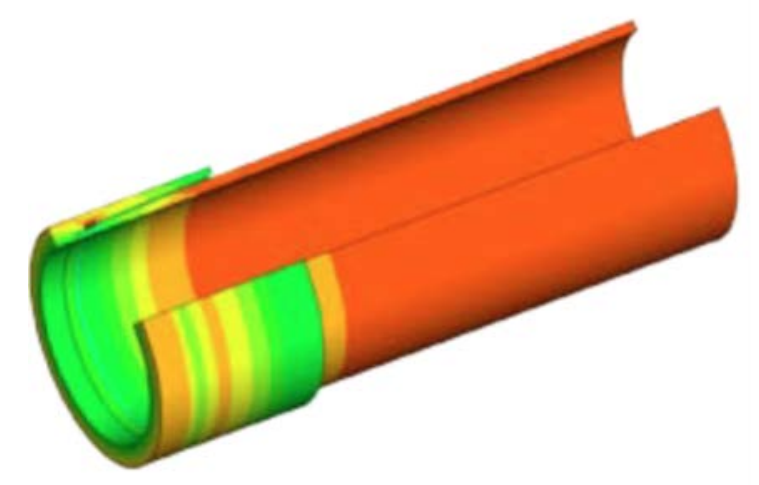

Figure 10. Example output with stress levels (red is high, green is low). 
The model confirms initial calculations performed earlier in this report regarding structural integrity of P110 casing (an example of the output is shown in Figure 10). However, the model predicts some plastic deformation resulting from the confining force on the expanding casing; but it showed no failure when subjected to a 2,000 psi pressure differential, which represents conditions during the hydraulic fracture stimulation. Upon cooling, the plastically deformed casing is slightly smaller than it was before the thermal cycle. Further modeling and research is needed to investigate how fatigue resulting from the thermal cycles and cumulative deformation would come into play.

One issue to consider is a completion that is not cemented and is prone to movement. Zonal isolation is needed, so in non-cemented wells in oil and gas unconventional wells, swellable external casing packers are used. External casing packers can be made to various lengths. Given the optimal length, friction, and sufficient swell pressure, the casing could be allowed to slide in place while maintaining zonal isolation. This configuration reduces the overall axial loading on the casing.

Swellable packers would be able to provide the wellbore isolation required in the hydraulic stimulation. We consulted with TAM International, a swellable packer manufacturer, to understand the details of their product offering in regard to this hypothetical situation. The differential pressure that the swellable packers can withstand is directly related to the length of the swellable packer. The length can be tailored to the application and wellbore conditions. 
Table 2. Casing cumulative displacement using swellable packers to allow motion

\begin{tabular}{|c|c|c|}
\hline Stage \# & $\begin{array}{c}\text { Lateral } \\
\text { Position (ft) }\end{array}$ & $\begin{array}{c}\text { Cumulative } \\
\text { Displacement (ft) }\end{array}$ \\
\hline 1 & 250 & 0.61 \\
\hline 2 & 500 & 1.23 \\
\hline 3 & 750 & 1.84 \\
\hline 4 & 1000 & 2.46 \\
\hline 5 & 1250 & 3.07 \\
\hline 6 & 1500 & 3.68 \\
\hline 7 & 1750 & 4.30 \\
\hline 8 & 2000 & 4.91 \\
\hline 9 & 2250 & 5.53 \\
\hline 10 & 2500 & 6.14 \\
\hline 11 & 2750 & 6.76 \\
\hline 12 & 3000 & 7.37 \\
\hline 13 & 3250 & 7.98 \\
\hline 14 & 3500 & 8.60 \\
\hline 15 & 3750 & 9.21 \\
\hline 16 & 4000 & 9.83 \\
\hline 17 & 4250 & 10.44 \\
\hline 18 & 4500 & 11.05 \\
\hline 19 & 4750 & 11.67 \\
\hline 20 & 5000 & 12.28 \\
\hline & & \\
\hline
\end{tabular}

With the packers fixed on the casing — or, typically, manufactured on 10-foot pup joints—we did not consider the stress due to expansion from $20^{\circ} \mathrm{C}$ to $200^{\circ} \mathrm{C}$ to be an issue because the casing is free to expand through the open hole. This situation avoids the plastic deformation as indicated in the finite-element model. Reviewing a temperature change from $200^{\circ} \mathrm{C}$ to $20^{\circ} \mathrm{C}$, we estimated that the packer would need to withstand the casing-impressed axial force before it is pulled out of position. Using a generally accepted friction factor, the length of packer required can be estimated and manufactured as needed.

To avoid this issue altogether, TAM offers swellable seal bore packers that allow axial movement of the casing while still holding pressure differential between stages. Continuing with the worst-case $20^{\circ} \mathrm{C}$ to $200^{\circ} \mathrm{C}$ temperature change, we can estimate the displacement and minimum length of seal bore at each stage (assuming 20 stages and the casing anchored on the heel side and free to move on the toe side).

Table 2 shows an example of this casing movement. The motion is anchored at the start of the horizontal section of the well (called the "heel"). However, this requires more understanding and modeling before making any recommendations at this point. 
On the topic of operations, all of TAM's FREECAP packers can withstand differential pressure after a few days but need up to a 40-day delay before they can withstand axial displacement. From a practical operational perspective, the sliding-seal bore packers can be the most robust, economic option. But this depends on the situational market costs and logistics of the hydraulic stimulation equipment and drilling rig.

In conclusion, the ANSYS finite element model shows that P110 casing will not fail but will likely plastically deform. This issue can be avoided altogether using swellable packers or seal bore swellable packers with freedom to slide while maintaining pressure isolation.

\section{Casing Wear Resistance}

The casing used in corrosive environments has a metallurgy that often has a lower wearresistance than conventional casings. The injector/stimulated well will have drilling mud, cleanout fluids, completion fluids, stimulation fluids, and cement pushed through it before production begins. Therefore, casing must be protected from operations given the long life span desired with a geothermal well. Damage from drilling can severely reduce the lifespan of casing. A nonrotating protector (NRP) has been shown to be a good casing protector (Renpu, 2011). Protection from other down-hole tools, such as coiled tubing and associated tools, should be addressed but will require development because very few options are offered in today's market.

\section{Cementing}

The cementing of casing in an HDR EGS can offer unique challenges. The challenges associated with these geothermal wells include the corrosive nature of the formations where the reservoir resides, the very high temperatures the cement must endure, the acceleration of "setting" at high temperatures, and methods to ensure that the cement covers the entirety of the casing. These challenges are in addition to normal cementing challenges encountered in the oilfield. The expansion with temperature, the stresses induced by thermal cycling, and the cement-to-casingto-rock bonding are issues that must also be addressed when selecting the proper cementing application in HDR EGS wells. We discuss the challenges associated with an effective longlasting cementing job, the current availability of geothermal-specific cement composition, and modern deep horizontal-well cementing techniques. We describe each challenge and offer a possible solution.

The thermal cycling of cement and its casing counterpart is a problem associated with geothermal completions. The expansion and contraction rates of the casing and cement are not the same, which makes the bond between the two a major source of concern. Thermal expansion and contraction can separate the casing from the surrounding cement if the expansion coefficient of the two materials differs. This separation introduces areas where corrosive materials can penetrate the exterior of the casing, leading to further separation and diminishing the casing's anchoring strength. Measures to minimize temperature cycling should be considered. Pretensioning of the casing string prior to cementation can prove to be beneficial by limiting compression due the thermal expansion.

In addition to considering a pairing of cement and casing with similar expansion rates, there are other methods used to decrease the failure of this bond - these include well-bore preparation through the use of mud conditioning, flushing, and mechanical cleaning tools. These techniques also help to ensure that the cement-to-formation bond is secure by removing the drilling 
mudcake. Techniques such as casing rotation and reciprocation are other methods to ensure an effective bond (Holt, et al., 2013). However, accomplishing this in the horizontal section of the wellbore will be challenging (if not impossible).

By definition, HDR EGS wells are drilled into formations not laden with fluids. This situation typically results in a relatively low formation pore pressure that can lead to the loss of circulation fluids and cement. Lightweight foamed cement can alleviate some of the loss of cement into the formation. Foamed cement has foaming agents and nitrogen or air added to the slurry, making the compound more viscous and less permeable. The low permeability of the cement means that the formation fluid is less likely to make contact with the casing, hence minimizing potential corrosive degradation. Foamed cement has a higher compressive strength compared to traditional cements due to the lesser amount of water in the cement slurry (Niggeman, et al.). Foamed cement is more ductile than conventional cement, which is advantageous due to extreme temperature cycling and the resulting expansion or contraction of the casing. Foamed cement also has a lower thermal conductivity due to its lower density, which means that the overall thermal cycling will be lessened (Halliburton, 2005). However, foamed cements are notoriously fickle to make and circulate (as shown with the Macondo disaster).

Another option to minimize lost cement to low formation pore pressure is a fiber additive to the cement. However, the inclusion of solids in the cement creates problems of its own, especially when pumped through a small orifice with the potential for clogging.

Ensuring that the annulus is completely filled with clean cement can prove challenging on any deep horizontal well. Traditional cementing involves putting a measured amount of cement into the casing and forcing it into the annulus from the "bottom-up" through the use of plugs. This method has the disadvantages of the high pressures needed to force the cement down the casing and up the annulus and that additional cement cannot be introduced in the same manner in the case of lost cement to the formation. Reverse circulation is a technique that overcomes these challenges by pumping the cement directly into the annulus. The reverse circulation technique requires lower pressures because gravity assists the placement of the cement, which results in less production-zone invasion by cement slurry. Placement times are shorter, allowing for more options in cement composition. Reverse circulation is particularly applicable to HDR EGS wells because casing must have a complete cement sheath from bottom to surface. This cement has two important functions: to give the casing mechanical support under the intense thermal cycling between production and shut-in and to protect the outside of the casing from corrosion by in-situ fluids (Finger, et al., 2010).

Thickening times can be a challenge to an HDR well due to high temperatures. The slurry should set slowly enough to allow time for the cement to properly fill the annulus, referred to as "pumpability," but set fast enough to protect the casing from shifts in the wellbore wall and to decrease downtime of operations. Cement composition can be adjusted to increase or decrease thickening times through the use of additives. The pumpability is associated directly with thickening time, allowing enough time for cement to fill up the space between the casing pipe and the borehole wall before the cement sets (Sugama, 2006).

The composition of the cement is as significant as the wellbore preparation and the cementing technique used with regards to the longevity of the product. The cement composition should 
inhibit in-situ fluid migration, have an appropriate thickening time, and be able to withstand the harsh conditions of a HDR EGS well. It is typical to use API Class G cement with additives to control properties of fresh or hardened cement slurry such as compressive strength, fluid-loss control, consistency, and thickening time (Alp, et al., 2013). Additives that have been proven to emphasize these attributes include silica flour or ground granulated blast furnace slag (GGBFS). The latter item is a byproduct of iron production and can be used as an additive or substitute for traditional Portland cement. GGBFS has been found to decrease porosity and increase compressive strength when used as an additive (Alp, et al., 2013). Neat GGBFS has slower thickening times, higher compressive strength, and no strength retrogression in comparison to Portland cement. GGBFS also can provide an elevated level of carbonation protection over traditional cement when blended with metakaolin (Bernal, et al., 2010). Halliburton (Halliburton, 2006) states: "When $\mathrm{CO}_{2}$ comes into contact with the traditional Portland cement that is used to cement well casings, it produces a deterioration phenomenon in the cement called carbonation. Over time, the loss of cement due to carbonation can cause serious damage to downhole tubulars and destroy zonal isolation integrity, resulting in costly remedial services or even abandonment of a well."

The DOE has funded research through Trabits Group, LLC, concerning "Development of an Improved Cement for Geothermal Wells.” The objective of this report is to "develop a novel, zeolite-containing lightweight, high temperature, high pressure geothermal cement, which will provide operators with an easy to use, flexible cementing system that saves time and simplifies logistics” (Trabits, et al., 2013). In essence, the research is looking to develop a low-cost effective geothermal cement that would not involve the recruitment of commercial operators. The findings of this study suggest that cement blended with $40 \%$ by weight of cement (BWOC) of $5-\mu \mathrm{m}$ particle-sized Ferrierite will provide adequate compressive and elastic strengths, and $0.6 \%$ BWOC of tartaric acid will provide extended thickening times adequate to a HPHT application. This research is ongoing, with updated results expected this year.

Several oil industry cementing contractors have developed EGS-specific cements and cementing techniques. Halliburton has developed their ThermaLock ${ }^{\mathrm{TM}}$ cement that is designed to retain its slurry weight under reservoir conditions, have high compressive strength, and resist corrosion from $\mathrm{CO}_{2}$. ThermaLock is formed from recycled fly ash, calcium phosphate hydrates, calcium aluminate hydrates, sodium polyphosphates, and mica-like calcium aluminosilicates. It has a working temperature range from $140^{\circ} \mathrm{F}$ to $700^{\circ} \mathrm{F}$. This cement is proven in HPHT environments and currently available.

ThermaSource Inc. is a cementing contractor involved in geothermal completions. Although articles have been published that support the success of ThermaSource's cementing, this cannot be confirmed after numerous attempts to contact the company. Schlumberger has a hightemperature cement that is designed to closely match the thermal expansion/contraction rate of casings. This product has been rated up to $600^{\circ} \mathrm{F}$ and has been effective in the Cymric Oil Field in the Kern County, California, where reservoir conditions are consistently over $300^{\circ} \mathrm{F}$.

Centralization of the casing in the wellbore will ensure that there is an even amount of cement surrounding the casing, resulting in an even expansion rate around the casing. The use of rigid casing centralizers can offer better assurance that the annulus will be completely filled with cement. Due to the nature of horizontal wells, the wellbore will be highly deviated, which can 
overstress or buckle common spring-type centralizers. "A rigid centralizer can ensure that the ratio of minimum clearance is 67\%, thus improving cementing quality” (Renpu, 2011). A rigid centralizer with rollers will ease the installation of casing by minimizing binding in deviated wellbore sections. However, this can lead to the risk of not getting the casing completely into the wellbore if hole restrictions are present (i.e., in an undergauge borehole).

\section{Corrosion Considerations}

Ideally, the chemical composition of the formation should be free of corrosives. The presence of corrosive substances in the formation - in particular, hydrogen sulfide and carbon dioxide gases-will lead to accelerated deterioration of completion equipment. Corrosive deterioration will be of utmost concern considering the longevity desired. The site selection will weigh heavily on the presence of corrosive materials in the formation chosen for the reservoir.

The presence of corrosive materials in the formation will change the metallurgy of the casing. Upon drilling and completing, the presence of these corrosive materials may be minimal. But over the course of a 30-year lifespan, the underlying materials within the formation can become a major problem. A thorough analysis of the formation and it composition should be undertaken to understand potential corrosion over the life of the well. Corrosion resistance will be required in most geothermal casings. Chloride ions, $\mathrm{H}_{2} \mathrm{~S}$ gas, and $\mathrm{CO}_{2}$ are the most likely corrosives to be present in HDR wells and will require that the casing comprise a specifically suited alloy blend. These alloys — for example, Inconel ${ }^{\circledR}$, Incoloy ${ }^{\circledR}$, and Hasteloy ${ }^{\circledR}$ — usually consist of a combination of chromium, molybdenum, nickel, and iron in various content percentages; but some alloys can also include titanium, copper, or other metals. Properties of these alloys change with temperature; hence, we advise a thorough analysis of the reservoir's composition and temperature. Alloy casings can be very expensive and can determine the financial feasibility of a potential HDR system. The Nickel Institute researches and publishes guidelines for corrosion resistant alloys (Craig, et al., 2011).

The control of corrosion will be determined by the quality of the cement, cementing procedure, casing protection, treatment of the fluid before re-injection, and the metallurgic composition of the down-hole assemblies. For production wells, operations should minimize, if possible, the introduction of corrosive chemicals from the injection fluids cycling through the fractures by chemical inhibition. If accomplished, the casing should last for a long time. 


\section{Injection Well Completion Techniques}

\section{Introduction}

We considered three injection well completion techniques for our study: “plug-and-perf," “sandand-perf," and "packer-and-port.” These techniques are all designed for the same purpose of creating a reservoir fracture network by hydraulic fracturing at multiple, hydraulically isolated zones in the wellbore, and they are all performed in the horizontal section of the wellbore. The hydraulic fracturing proceeds one zone at a time (called "stages”) using the various techniques. The process starts at the "toe" of the well (the total depth) and works its way back to the point where the well starts horizontal, called the "heel" or the "landing zone" in directional drilling.

The differences in these three techniques are in the zonal isolation. The "plug-and-perf" method uses bridge plugs or retrievable packers to seal off a stage to enable the next stage to be stimulated. The "sand-and-perf" method uses tightly packed sand in the casing to isolate a fractured stage. In both of these cases, the external annulus between the casing and open rock is sealed with cement from toe to heel. The "packer-and-port" method uses a multistage fracturing system with external packers to isolate stages without cementing the casing in place. We examine these methods in following sections.

\section{Plug-and-Perf Design}

The "plug-and-perf” technique uses a cemented casing throughout the length of the injector wellbore. The formation is then stimulated using a multistage fracturing and perforating process. This process is the most technologically advanced technique proposed, providing the best zonal isolation throughout the hydraulic fracturing process.

The first step of this technique (Figure 11) is to case the entire wellbore from bottom hole to surface. This casing can be as one section or as a liner hung off in an intermediate casing string (typically vertically). This entire length of casing-from the vertical section through all of the horizontal section - should then be cemented from toe to a sufficient height to isolate the pay zones in one procedure; this can be difficult due to the volume of cement, time needed to inject the volume, and temperature in the reservoir. After confirming wellbore integrity (e.g., pressure tests, cement bond logs), the formation is then perforated and stimulated in a single trip near the toe of the well, thus creating the first stage. The perforation guns are pushed into place by pipee.g., by coiled tubing (CT), workover strings, or drill pipe. The first stage at the toe may be stimulated using a rupture disc valve assembly that is also installed with the casing near the toe. After stimulation, a retrievable or drillable packer (plug) is then installed above the first stage, the next stage is perforated and stimulated, and the process repeats until the desired number of stages are achieved. In some cases, in the Bakken fields of North Dakota, more than 40 stages have been accomplished. 


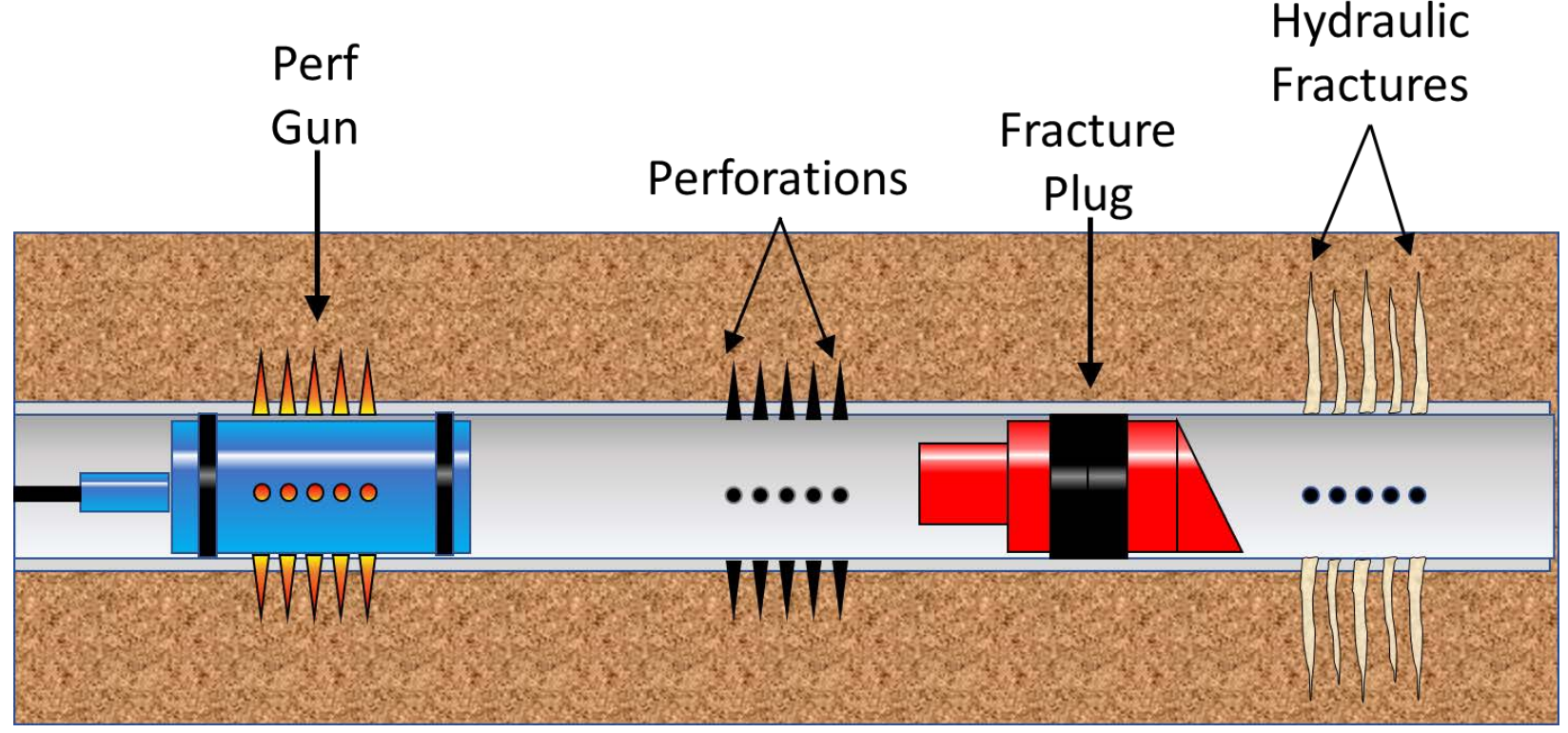

Figure 11. Plug-and-perf technique for hydraulic fracturing.

This completion design will have the highest cost of the three proposed designs, but it offers the most technological security. Casing and cementing the horizontal wellbore ensures that the completion tools downhole are protected from any change in reservoir stability, and downhole tools can be retrieved, if needed, more easily than in an open hole. The completion string will be operated at cooler temperatures than in an open hole because cooler injected fluids will surround the string inside the casing during production. The retrievable packers offer better isolation during hydraulic fracturing than the "sand-and-perf" technique, especially in horizontal sections.

The disadvantages of this design are the cost and the time of installation. The completion equipment specific to this design are costly due to the amount of equipment needed to hydraulically fracture the reservoir. Each stage requires an individual wireline or CT trip down hole and back out, which takes a considerable amount of time and is consequently costly. The casing and cement in the horizontal section add considerable costs over an open-hole design. In addition, $100 \%$ cement coverage is difficult in the horizontal annulus region.

An alternative to this process is to perforate all stages first, deploy the completion string consisting of ball-actuated fracturing valves (see Figure 13) and liner packers, then hydraulically fracture through the completion string. The completion string would essentially be the same as the previous method although the abrasion of the stimulation fluid with proppant may cause some premature degradation of the sliding-sleeve system. The drop-ball acts to seal off the well downhole, eliminating the need for packers inside the production string. The hydraulic fracture schedule will commence as follows: drop the first (smallest) ball to actuate the valve nearest the toe, pump the prescribed hydraulic fluid and proppant, drop the next-size-larger ball to actuate the next valve and seal off downhole stages in the production liner, pump the prescribed hydraulic fluid and proppant, repeat until all stages are complete, retrieve or use degradable drop-balls, and drill out ball-catch assemblies, if necessary. 
The advantage of this alternative over the traditional "plug-and-perf" method is the decrease in the number of trips downhole to hydraulically fracture each stage. The perforations could potentially be performed in one trip before deploying the completion string. The stimulation of the individual stages can be performed without another trip downhole. A disadvantage of this alternative is the pressure increase needed to push the stimulation fluid through the sliding sleeve port before the perforations, in addition to the wear, this puts on the sliding sleeve itself. Both designs will require that the stimulated stages align between the packers of the completion string. If the ball-catch assembly needs to be drilled out, the loss of zonal flow control is lost without intervention.

A second alternative to this method requires implementing a cemented-in-place sliding-sleeve system. This system essentially cements the completion string in the wellbore. This newer technology is being developed by Packers Plus, among others. Some major advantages to this system are that it eliminates the 1) need to perforate, 2) installation and removal of bridge plugs, and 3) use of coiled tubing or wireline services to hydraulically fracture. This system also minimizes the amount of elastomer downhole, which tends to degrade in high-temperature environments. The system would comprise the same drop-ball-actuated sliding sleeves spaced to the individual stages by casing without the need for packers. The hydraulic fracturing schedule would proceed normally with the drop-ball system. The one disadvantage of this system is that when initiating hydraulic fracturing, the fluid would have to first penetrate the annulus cement through the port before the fluid would penetrate the formation. Reverse-circulation cementing would be very beneficial with this method to eliminate the deployment of a wiper plug used with traditional cementing and to minimize the amount of the cement's contact with the internal sliding-port system.

\section{Sand-and-Perf Design}

The "sand-and-perf" completion approach uses the same wellbore set-up as the "plug-and-perf" approach but differs by the stimulation technique. This method uses a sand plug to isolate fractured stages rather than a retrievable packer and has the advantage of being technically simpler by eliminating the installation and removal of the isolating bridge plugs (Figure 16). It is popular in vertical wells because gravity helps to deliver the sand to location, and the sand maintains its position without migration. In essence, the goal is to deliberately "screen out" the wellbore, but to do so in a controlled fashion. 


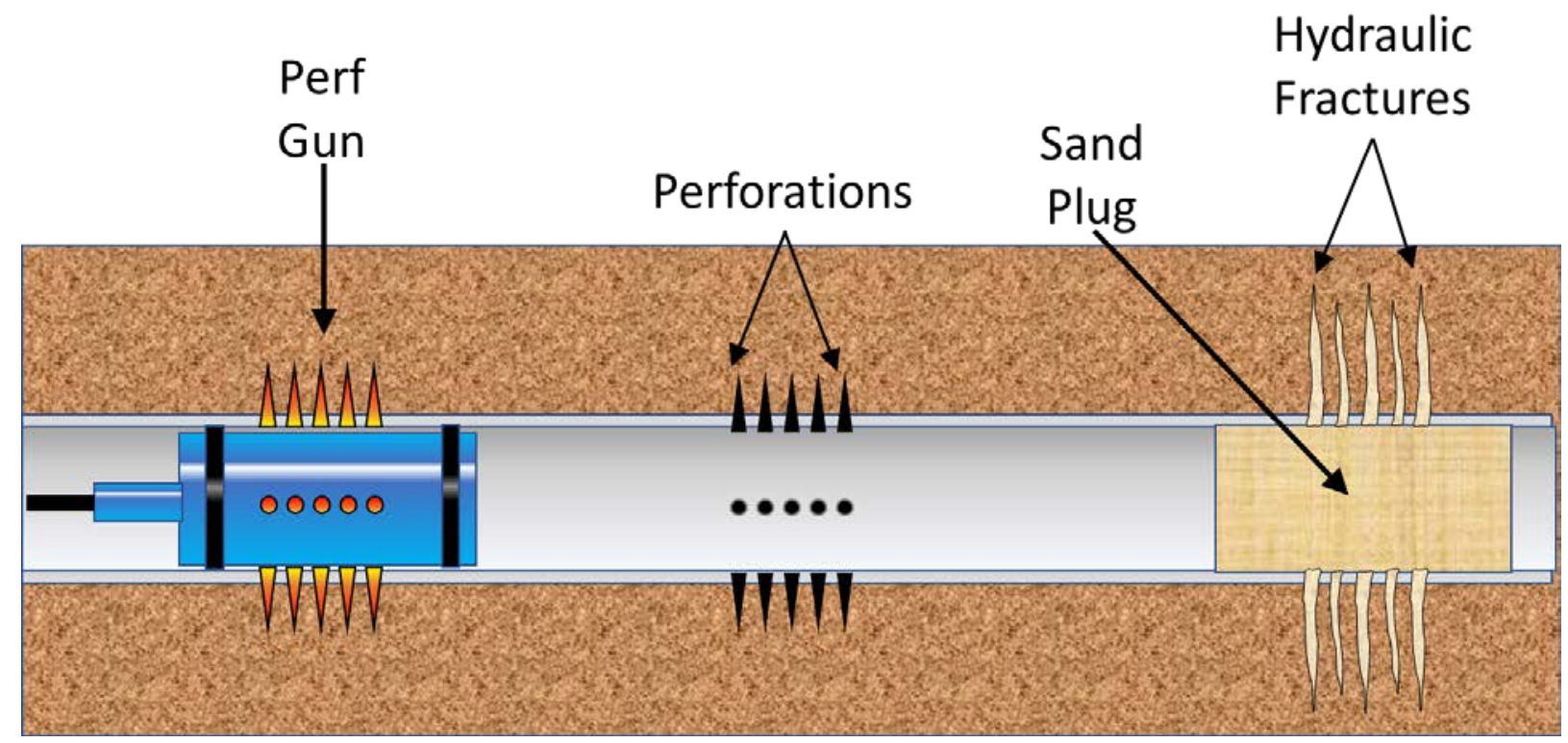

Figure 12. Sand-and-perf technique for hydraulic fracturing. Once a stage has been fractured, it is isolated with packed sand before perforation and stimulation of the next stage (Mathur, et al., 2013).

The first step of this technique is to case the entire wellbore, as before. This entire length of the casing should then be cemented in one procedure from the toe to a height sufficient to isolate the horizontal section. The formation is then perforated and stimulated in a single trip near the toe of the well, creating the first stage. As before, the first stage at the toe may be stimulated using a rupture disc valve assembly that is installed with the casing near the toe. An amount of sand is then injected into the wellbore to isolate the first stage from the next stage's stimulation. The next stage is perforated and hydraulically fractured, followed by more sand to isolate the newly created stage. The process is repeated until achieving the desired number of stages.

The sand must then be extracted up the wellbore. This extraction is accomplished by using a pressurized nozzle on coiled tubing to loosen the sand, suspend the sand in the fluid, and flush the sand/fluid mix out of the wellbore, similar to the transport of cuttings while drilling. After sand removal and cleanout, the completion string is deployed. The completion string consists of a combination of sliding-sleeve port sections on a production liner and a zonally isolating packer between the casing and liner.

The horizontal wellbore design presents challenges to the efficiency of the "sand-and-perf" completion design. As sand is packed to isolate a stage, the sand is inevitably forced into the fractures, which can be problematic to flush. This is not as much of an issue for oil and gas wells because the hydraulic fracturing is performed in producing wells - the sand will naturally flush itself out as oil is produced. But in the case of fracturing through the injector well, the sand will be forced deeper into the fractures, potentially plugging induced fractures. This technique is performed fairly easily in vertical wells because gravity assists the placement of the sand; however, this is not the case in horizontal wells. The sand will tend to settle out in a horizontal wellbore, creating a problem for effective zonal isolation; the long distance between induced fractures in an EGS setting could help alleviate this problem. The transport of the sand plug 
along a horizontal wellbore can be challenging because it is not gravity assisted. BJ Services has been addressing the sloughing problem by developing their LitePlug composite sand. "The (LitePlug) technology has been used to stimulate hundreds of stages, with typical completions featuring eight or nine stages at 300-ft stage spacing” (Castaneda, et al., 2010), which is similar to the proposed completion schedule developed for EGS models.

The advantage of the "sand-and-perf" method is the simplicity of the system. Mechanical packers can get stuck prematurely in the casing, can be difficult to remove if retrievable or need to be drilled out if drillable, and are costly when compared to sand plugs. Also, no trip downhole is needed to set the sand plug. Although the sand must be flushed out after the fracture schedule is complete, the time and cost are typically less than removing mechanical plugs.

\section{Packer-and-Port Design}

The "packer-and-port” completion approach uses an open horizontal hole and zonally isolates areas through the use of external packers and a liner. This method differs from the other two methods by not using cemented casing; hence, it eliminates the cost and tasks of casing, cementing, and perforating in the horizontal section. The individual stages would be hydraulically fractured one at a time by using the sliding-sleeve ports or drop-ball valves.

The "packer-and-port” approach allows completion in the least number of steps of any of the proposed techniques. The non-horizontal casing and cementing procedures of all three techniques are identical; however, the horizontal section of this approach is left as an open hole. The open hole section is then cleaned of drilling fluids before the completion string is deployed. The completion string consists of a production liner with numerous sliding-sleeve ports and external packers to isolate individual stages. The process of setting the external packers involves either pressurizing the well (the specific procedure will be determined by the manufacturer of the equipment) or allowing the wellbore fluids to be imbibed into the elastomer seals, swelling the elastomer to isolate the different stages (Figure 17). Once the packers are set, the stages are effectively isolated, and the hydraulic fracturing process can begin. Hydraulic fracturing and acidation commence through the sliding-sleeve port system-one stage at a time beginning at the toe. 


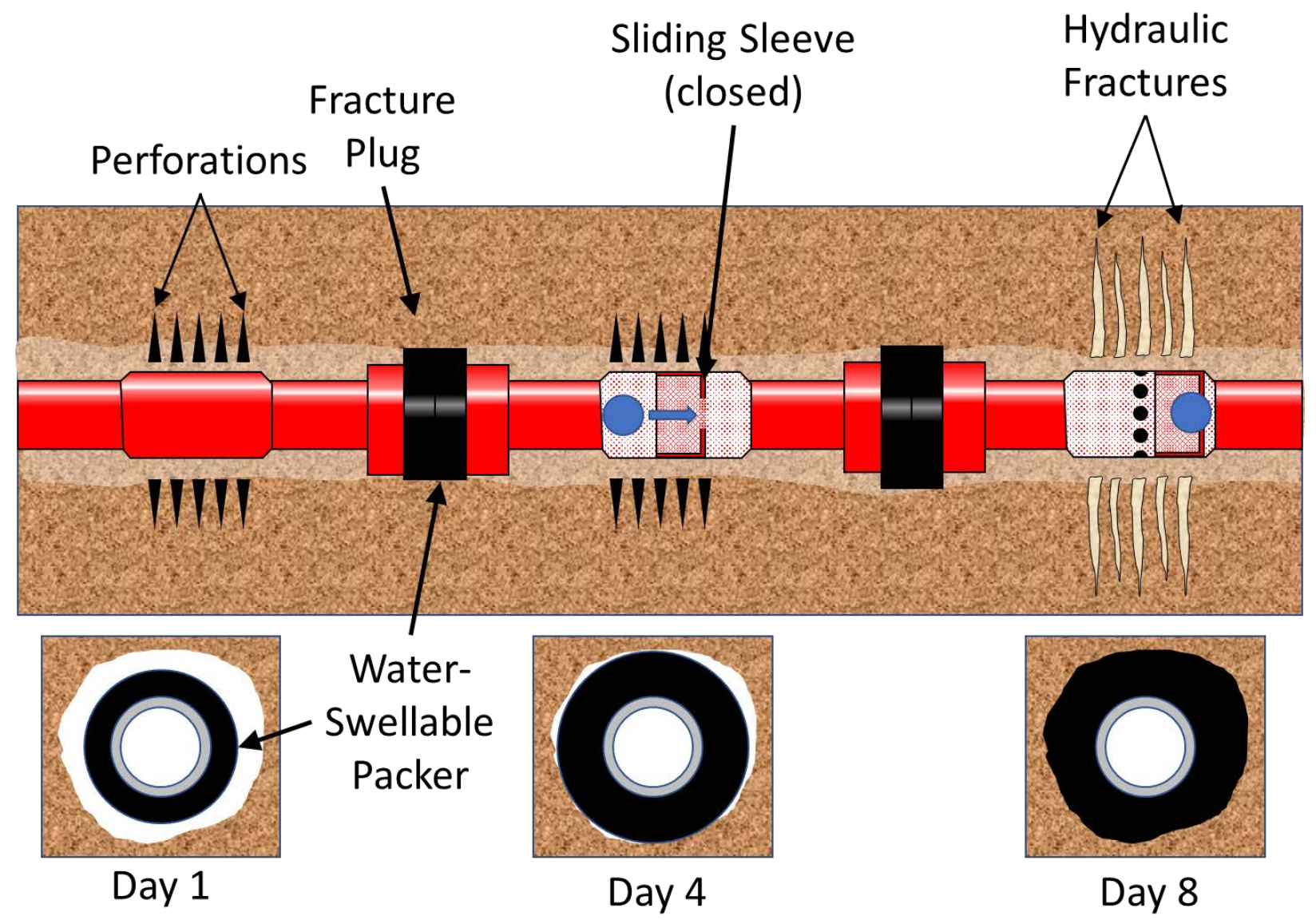

Figure 13. Multi-zonal packer-and-port system with water-swellable packers (Strategic Oil Solutions, 2013).

Drop-ball-actuated ports would be advantageous for controlling the sliding sleeves due to the ease of use. The drop-ball-actuated ports can support many stages and can be controlled via degradable balls that will deteriorate downhole. The drop-ball acts to seal off the well downhole, eliminating the need for packers inside the production string. The hydraulic fracture schedule commences as follows: drop first (smallest) ball to actuate the valve nearest the toe; pump the prescribed hydraulic fluid and proppant; drop the next-size-larger ball to actuate the next valve and seal off downhole stages in the production liner; pump the prescribed hydraulic fluid and proppant; repeat until all stages are complete; retrieve or use degradable drop-balls; and drill out ball-catch assemblies, if necessary.

The EGS model being proposed will consist of one injection well and two or more producers. The liners will require external packers and sliding-port sleeves. This system will allow the isolation of each stage in order to maximize the flow from injection to producer and minimize fluid loss to the formation. Ideally, the sliding-sleeve port system would be controlled from the surface, thus requiring an intelligent well design. However, the sliding ports could be controlled via wireline or coiled tubing. The control of the isolated stages needs to be designed to allow fluid to flow past a closed stage to a downstream stage, except in the case of the last or toe stage. 
This means that traditional ball valves will not be an option down hole; however, a set of ball valves designed to isolate only one stage could be employed.

This completion approach is the least involved of the three proposed techniques. The elimination of cemented casing in the horizontal section of the wellbore is a significant simplification of the completion system. The casing in the horizontal section encounters the most significant corrosion potential of the overall casing design due to its direct exposure to the formation. The horizontal casing is also difficult to centralize, will undergo wear from remediation, and requires perforation. The hindrance of filling the annulus entirely with cement in the horizontal section is alleviated. The cost of completion is minimized with the "packer-and-port" system. Fractures can be initiated in each stage, nearly guaranteeing that each stage has at least one of its own fractures. This system also has advantage of using an open hole in isolated section, so that the fracture can initiate at the "weakest point" in the formation, likely accessing an existing fracture in the formation.

Some additional disadvantages to this approach should be considered. The zonal isolation of the induced fracture network will be determined by external packers. This system uses sliding-sleeve port sections on the production liner with external packers to seal the annulus. The seal between external packer and wellbore can be troublesome for complete zonal isolation because the rough texture of the wellbore wall can create voids that fluids can transfer through. Induced fractures can initiate next to or behind the external packer, creating shortcomings in the zonal isolation as well. In addition, the external casing packers will need to withstand not only the temperatures and pressures without fluid bypassing, but also, they must resist the movement of the liner due to thermal cycling. The length of the external elastomer can be varied and must be determined before deploying this type of system.

The temperature resilience of a "packer-and-port” system has yet to be proven. Currently, the highest-temperature-rated completion tools are capable of $315^{\circ} \mathrm{C}$ and 10,000 psi. These are Packers Plus' Inferno completion tools specifically designed for an EGS system in the Cooper Basin of Australia (Packers Plus, 2014). The product was installed in April 2013, operated for 160 days at $275^{\circ} \mathrm{C}$-plus bottomhole temperature, and was shut down to evaluate system performance. Although the product test was a success, the longevity of the products has yet to be proven.

Every major service company has a version of a sliding-sleeve system because this is a common need in the oil industry. The differences in these systems lie in the port size, port orientation, completion-string adaptability, differential-pressure tolerances, and the working temperature ranges. The most common difficulty to overcome is the temperature range, and several companies currently produce sliding sleeves rated up $200^{\circ} \mathrm{C}$-plus. Weatherford has sliding-sleeve systems that can operate up to $370^{\circ} \mathrm{C}$, which exceeds the scope of this research (Neil, 2014).

Baker Hughes has an intelligent sliding-sleeve system rated up to $260^{\circ} \mathrm{C}$; the use of this product limits the number of stages to ten or less (Gill, 2014).Packers Plus has the Inferno ${ }^{\mathrm{TM}}$ Multi-Stage Completion System, which has sliding sleeves rated up to an unconfirmed $350^{\circ} \mathrm{C}$-plus (Packers Plus, 2014). Halliburton's sliding-sleeve systems are limited to $204^{\circ} \mathrm{C}$ due to the O-ring elastomer composition (Halliburton, 2012). 
The availability of external packers capable of high temperatures is the most limiting component of the proposed system. Packers Plus has the best-suited packers for an EGS system. Charles Mullen of Packers Plus recommended a 36-inch water-swellable packer for zonal isolation but offered that packers could be built to lengths of 30 feet (Mullen, 2014). This option would create the best currently available zonal seal in an open hole or cased wellbore. The maximum temperature range of the Inferno ${ }^{\mathrm{TM}}$ bridge plugs and swellable packers is up to $572^{\circ} \mathrm{F}$, but this has not been confirmed. Packers Plus also has a line of sliding-sleeve systems rated to the same temperatures.

\section{Currently Available Completion Components}

The currently available oil-industry completion components applicable to an HDR EGS are sufficient. A majority of these products are built-to-suit and not off-the-shelf, but they are commercially available based on purchase orders. The products that are available immediately include casing, bridge plugs, and stimulation products.

The specific casing design applicable to an EGS can use available oil industry casing. There appears to be no need for further development in this aspect of the proposed EGSs. A detailed casing design will need to be engineered, as for any deep well, as was discussed in the previous section. The parameters of tensile, collapse, and burst pressures will need to be evaluated specific to the reservoir conditions, in addition to corrosive resistivity, thermal-cycling considerations, couplers, and size of casing to attain desired flow rates.

\section{Stimulation and Perforation Considerations}

The casing perforations in an EGS will require more total surface area than in a comparable oil well. This requirement is because of the amount of fluid to be transferred through the wellbore, and it can be accomplished by either perforating more holes or perforating larger holes.

Perforating larger holes is preferential due to the lower pressure required to push fluid through the perforation into the formation. A large number of smaller holes could compromise the integrity of the casing and cement.

Perforating charges that can withstand the reservoir conditions of an EGS are currently available. Several companies make HPHT perforating systems. GEODynamics has a wide variety of perforating systems with charges available up to $600^{\circ} \mathrm{F}$ for one hour and $550^{\circ} \mathrm{F}$ for ten hours (GEODynamics, 2007). Perforating charges are available to create entrance holes of up to 1.39 inches diameter in a 9 5/8" casing. (GEODynamics, 2013). Schlumberger has charges rated up to $500^{\circ} \mathrm{F}$ known as the PowerJet ${ }^{\mathrm{TM}}$. Baker Hughes does not offer any charges above $500^{\circ} \mathrm{F}$, but a representative spoke of success with a process of cooling the wellbore prior to deploying the perforating system (Gasmi, 2014). This process could be adapted to use a wide range of charges.

An alternative to perforating charges is a sandjet perforating system. This system uses a CTdeployed sandjet nozzle system that uses a pressurized sand slurry to cut through the casing and open a cavity in the formation. The advantages of this system is that there are no explosive to constrain time or temperature limitations, there are no pressure limitations, the perforations are burr-free minimizing pressure losses at perforations, and there is no need for electronics downhole for igniting charges. A sandjet system also "removes associated challenges related to 
the transportation of explosive materials, which requires a military escort in some regions.” (Weatherford, 2011).

Regardless of the technique used, pressure loss through perforations is a potential concern for the completion techniques considered. To address this, a model for estimating pressure losses in the well, from the surface through the perforations, was developed. For the flow rate per fracture assumptions used in our study, we found that pressure losses through perforations were under 100 psi-not negligible, but not large enough to be of major concern. For comparison, we estimated the pressure drop through the perforations to be about twice as much as a pressure drop from friction losses to the pipe/casing. 


\section{Production Well Completion Techniques}

\section{Introduction}

The three injection well completion techniques covered in the section above are also applicable to the production well. Additionally, a simple open hole completion could be used. The purpose of the well is production, so the advantages and disadvantages of the completion techniques studied differ slightly from those for injection wells.

\section{Open Hole}

An open hole completion simply means that no casing is run. The full diameter of the borehole is open to production flow, which means that there are no barriers between the rock and borehole. This also makes it easier to deepen the hole, if needed. However, wellbore instability can be a significant problem unless the wellbore walls are completely stable under all thermal, flowrate, and pressure conditions. In addition, there is no control to prevent crossflow and low sweep efficiency along the created fracture planes.

\section{Hydraulic Isolation Techniques}

Hydraulic isolation is a more likely scenario because this is the most common type of wellbore completion. It has the advantage of simplicity, reasonably low cost, and flexibility in fluid control. However, hydraulic isolation between the casing and open hole is imperative, which requires either a good cement job or external casing packers. Examples of horizontal completion techniques are repeated here.

\section{Plug-and-Perf Design}

The "plug-and-perf" technique uses a cemented casing throughout the length of the production wellbore. The formation can be perforated in selected locations, such as where stimulated fractures or flow zones have been identified. The perforations can be situated in any location to desired length, shot density, and shot phasing. A potential disadvantage is that cementing the casing in place could plug the fracture network created during stimulation, or only allow flow through the perforation zones, limiting flow into the production well. The perforated production wells zones could be stimulated to increase connectivity with the fracture network created from the injection well.

\section{Sand-and-Perf Design}

The sand-and-perf design has the same advantages and disadvantages as the plug-and-perf design, with the exception of the use of sand to isolate the zones. The sand could be forced into the fractures but would likely be flushed out as fluid is produced.

\section{Packer-and-Port Design}

The "packer-and-port" completion approach zonally isolates areas by using external packers and a liner. This method differs from the other methods by not using cement for zonal isolation; hence, it eliminates the cost and tasks of casing, cementing, and perforating in the horizontal section. If stimulation of the production well is desired, the individual stages would be opened one at a time by using the sliding-sleeve ports or drop-ball valves. If the production well is not to be stimulated, the port system could be omitted. A distinct advantage of the packer-and-port system is that it gives the production well access to almost the entire length of the wellbore for 
production flow, similar to an open hole completion. But it still allows the possibility of zonal isolation to control flow through individual stages of the formation, assuming the ports can be controlled individually. As discussed for the injection well, the use of sliding sleeves does give a measure of flow control over the length of the horizontal section. For example, with a closing capability designed into the sleeve, cold-water breakthroughs could be closed off by shutting off the appropriate sleeve. This assumes the fractures are sufficiently isolated from others and that the sleeves still have pressure and mechanical integrity. In the oilfield, there is a new technique called "Intelligent Wellbores," where sliding-sleeve or similar ports can be manipulated from surface action to be opened or closed. In addition, sensors are located downhole to monitor conditions. This technique is still being proven for oilfield application and is not yet ready for geothermal applications.

\section{Fracture Connectivity (Frac Hits)}

Enhanced geothermal systems require the connectivity between two wellbores to produce heated water at the surface. This can be achieved either naturally through permeable media or through an existing fracture network when these characteristics exist in the formation. In granitic formations, matrix permeability is essentially non-existent, and intervention is required to allow fluid flow between wellbores. Existing natural fracture networks are common in granitic reservoirs, but the fracture network is often discontinuous and cannot reliably deliver fluids via pressure differential from one wellbore to another. Therefore, an induced fracture network is necessary to create a passage between wellbores, otherwise known as fracture connectivity.

Fracture connectivity is achieved by hydraulically fracturing the formation. Hydraulic stimulation can be performed through either one or both of the to-be-connected wellbores. In the case of fracturing from both wellbores, the occurrence of stress shadowing could be problematic. Fracture propagation occurs in the direction of the lowest in-situ stress; however, although fractures propagate outward, the induced stress near the fracture tip increases in turn, which minimizes the likelihood of two fractures intersecting at their tips. Consequently, inducing a connecting fracture network through two hydraulic fracturing processes is unlikely, thus making the process feasibility low.

Hydraulically inducing a connecting fracture network from one wellbore to connect with the second wellbore is preferential. An advantage of this technique is that the formation's in-situ stresses are unchanged at the time of stimulation. By understanding the formation's in-situ stresses, a model of the expected fracture propagation can be established. From this model, the two parallel wellbores' placement in the formation can be established to maximize the likelihood of fracture connectivity. Additionally, stimulating through one wellbore to connect with an open hole wellbore can also serve to increase the fracture connectivity between wellbores. An open hole wellbore will result in a lower stress in the near-wellbore area, which promotes fracture propagation to the wellbore. Minimizing hydraulic pressure within the wellbore will further promote fracture propagation to the wellbore. In an EGS reservoir, the plan would be that all wells would be drilled before stimulation. The hydraulic fracturing of the reservoir will be initiated from the injector well. The production wells would be depressurized to increase the chance of a fracture "hitting" the production wellbore.

The oil and gas industry has been aware for some time of wellbore connectivity through hydraulically induced fractures (Jacobs, 2017). However, the fracture connectivity observed by 
industry is typically detrimental to oil and gas production; consequently, research within the industry is conducted to avoid such occurrences. Fortunately, data surrounding fracture connectivity between wellbores are available and can be used to reverse engineer the opposite of what the oil industry is researching. By determining the particular characteristics of the situation in which the connectivity occurred, one can develop a plan to attempt to achieve the same result. Researchers at Schlumberger "concluded that hydraulic fracture system (connectivity) was most likely due to stimulation fluid flooding into depleted fracture systems around parent wells, resulting in a reduction in the effective fracture area (of the stimulated well)" (Peza et al., 2015). The depleted fracture systems refer to the area of low pressure near the wellbore that equates to the decreased wellbore pressure suggested here. 


\section{Fracture Creation Modeling}

A commercial hydraulic fracture simulation package-Mangrove, by Schlumberger-was used in an EGS model with largely distributed pre-existing natural fractures to model fracture propagation during the creation of a complex fracture network. The main goal of this study is to investigate optimum treatment parameters in creating multiple large, planar fractures to hydraulically connect a horizontal injection well and a horizontal production well that are 10,000 $\mathrm{ft}$ deep and spaced $500 \mathrm{ft}$ apart from each other. We carried out a matrix of simulations for this study to determine the influence of reservoir and treatment parameters on preventing (or aiding) the creation of large planar fractures. The reservoir parameters investigated during the matrix simulations include the in-situ stress state and properties of the natural fracture set such as the primary and secondary fracture orientation, average fracture length, and average fracture spacing. The treatment parameters investigated during the simulations were fluid viscosity, proppant concentration, pump rate, and pump volume. A final simulation with optimized design parameters was performed. The optimized design simulation indicated that high fluid viscosity, high proppant concentration, and large pump volume and pump rate tend to minimize the complexity of the created fracture network. Additionally, a reservoir with "friendly" formation characteristics such as large stress anisotropy, natural fractures set parallel to the maximum horizontal principal stress $\left(\mathrm{S}_{\mathrm{Hmax}}\right)$, and large natural fracture spacing also promote the creation of large planar fractures while minimizing fracture complexity.

\section{Heat and Mass Flow inside EGS}

The main goal in EGS operations is to circulate the fluid through the hot formation to extract and produce thermal energy. This process is highly dependent on the interaction of heat conduction inside the rock matrix and heat convection by the injected fluid. Simply maximizing the total stimulated reservoir volume will not guarantee that all the injected fluid will circulate throughout the complex fracture network. Doe et al. (2014) modeled a complex fracture network set inside a geothermal reservoir and noticed that in early times of heat production, the thermal behavior is highly dependent on the high-intensity fracture network within the stimulated volume. However, once the stimulated volume thermally depletes, the entire reservoir acts as a single thermal sink. Because the flowrate inside the reservoir depends greatly on the fracture aperture and number of flowing conduits (Gringarten et al., 1975), a complex fracture network containing many nonparallel fractures and various apertures can result in many flow paths with different flow rates and flowing distance. Heated fluid from one fracture can combine with the colder fluid from a different flow path before being produced to the surface, eventually reducing the total efficiency of the heat extraction between the injected fluid and the heated matrix.

High flow rates during heat production in geothermal reservoirs tend to accelerate the early thermal breakthrough effect because the rate of thermal convection between the heated matrix and cold fluid is faster than that of thermal conduction within the heated matrixes. If the flow rate of inject fluid is too high, it is more likely to sharpen the thermal front inside the heated formation and eventually reduces the total heat-extraction volume. Therefore, a relatively low flow rate is preferred during heat production to reduce early thermal breakthrough. Yet, in complex fractured reservoirs, due to the large number of non-uniform fractures and the preferential flow behavior for fluid in finding the least-resistant path, it is difficult to artificially control the fluid flow in each fracture conduit to have uniform flow rates. Therefore, the 
stimulated reservoir volume can be much larger than the actual heat-extraction volume in geothermal reservoirs (Figure 14) (Riahi et al., 2014).

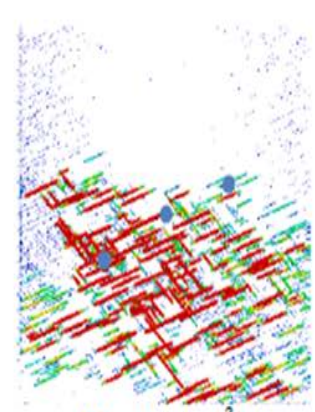

(a) $2 \mathrm{e}-4 \mathrm{~m}^{3} / \mathrm{s} / \mathrm{m}$

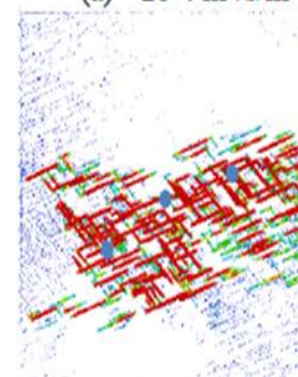

(c) $8 \mathrm{e}-4 \mathrm{~m}^{3} / \mathrm{s} / \mathrm{m}$

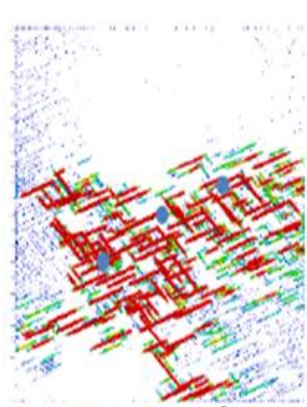

(b) $4 \mathrm{e}-4 \mathrm{~m}^{3} / \mathrm{s} / \mathrm{m}$

Aperture (m)

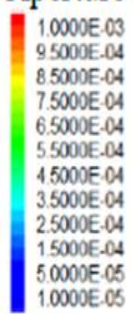

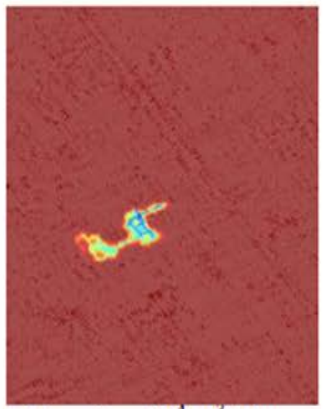

(a) $2 \times 10^{-4} \mathrm{~m}^{3} / \mathrm{s} / \mathrm{m}$

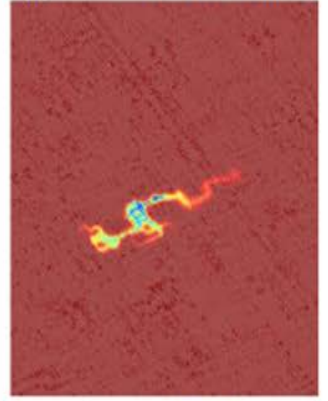

(c) $8 \times 10^{-4} \mathrm{~m}^{3} / \mathrm{s} / \mathrm{m}$

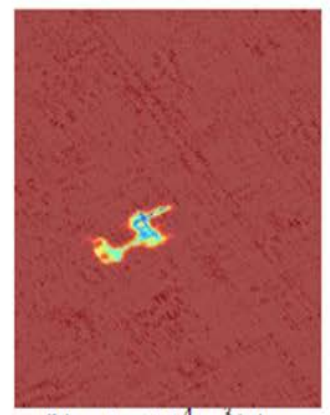

(b) $4 \times 10^{-4} \mathrm{~m}^{3} / \mathrm{s} / \mathrm{m}$

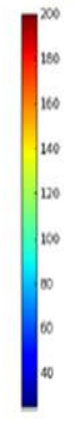

Figure 14. Comparison of shear stimulated volume (left) and rock temperature during circulation (right) for fracture networks created with different stimulation injection rates (Riahi et al., 2014).

\section{Conceptual Design for EGS Solution}

Complex fracture networks do not necessarily contribute to a better heat production in EGS application as discussed before. On the contrary, it might result in wasted fluid and proppant during stimulation operations if the created stimulated reservoir volume is much larger than the actual heat-extraction volume. It also has potential to accelerate early thermal breakthrough effects if the flow rate inside the complex fractured reservoir is much higher than the expected production rate for effective heat exchange between injected fluid and matrix. Due to the potentially detrimental effects of complex fracture network on reservoir creation and heat production, it is critical to understand the physical mechanisms behind the creation of the complex fracture network and then find effective solutions to reduce the level of complexity of the created fracture network.

Interactions between hydraulically induced fractures (HFs) and pre-existing natural fractures (NFs) are one of the main reasons for the complex fracture network occurrence during hydraulic fracturing treatments. These interactions also explain the complex fracture networks present in many reservoirs with proven existence of largely distributed natural fractures in the microseismic monitoring of hydraulic fracturing operations. To minimize the creation of complex fracture networks during EGS application, it is desirable to perform hydraulic fracturing treatment in reservoir with a relatively small distribution of pre-existing natural fractures. However, case studies of the hydraulic fracture simulations showed a high potential for those largely distributed natural fractures to exist in unconventional reservoirs, and an even higher potential in granitic system (Hannes et al., 2013). Therefore, to effectively use 
unconventional stimulation techniques in EGS reservoir creation while avoiding the negative effects from complex fracture network, in this study we considered large planar fractures to be the most effective fracture geometries. The target EGS design for this study contains a horizontal injection well in the center, connected to one or two horizontal production wells as shown in Figure 2. The induced multiple fractures from the injection well are expected to be planar and large enough to reach the production well on the side.

\section{EGS Model Design}

The EGS model design consists of a horizontal well that is 10,000 $\mathrm{ft}$ deep with 10 degree per $100 \mathrm{ft}$ well deviation and a 3,000-ft-long horizontal section in the simulator. The horizontal section of the well is in the direction perpendicular to the SHmax (maximum horizontal stress). An illustration of the general design for the well is shown in Figure 3 and Figure 4 shown earlier.

Fracture creation was modeled using Mangrove, a commercial software package available from Schlumberger. We started our simulations with a multi-stage hydraulic fracture design of 13 perforation clusters with 200-ft spacing as shown in Figure 15. The blue curve represents the injection well with hydraulic fracturing treatment, and the yellow curve represents the production well located $500 \mathrm{ft}$ lateral to the injection well. Note that we used a symmetrical completion sequence during this simulation, consisting of fracturing from the toe to the heel for the first 6 fractures (fractures 8-13), and then fracturing from the heel to the toe for the last 7 fractures (fractures 1-7). This is not necessarily practical for field operations, but it allowed us to observe the effect of no stress shadowing (fractures 1 and 13), stress shadow effects from one side of the fracture being created (fractures 2-6 and 8-12), and stress shadow effects from both sides of the fracture being created (fracture 7). Other examples of using the symmetric sequential fracturing to investigate the role of natural fractures and other critical operational factors have been reported in Hu and Tutuncu (2016). A more practical field-completion sequence was included in the optimized designs later. To create a successful EGS reservoir, most of the created fractures from the horizontal well must propagate with a fracture half-length long enough to reach the production well.

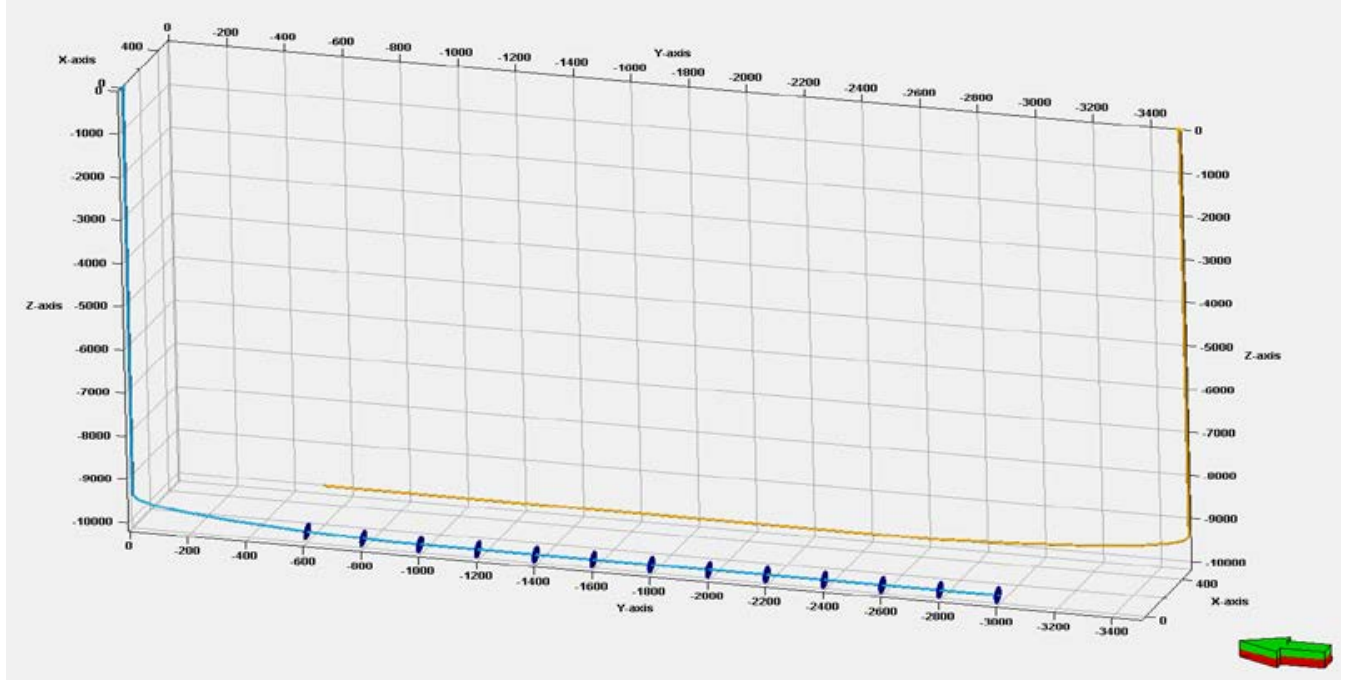

Figure 15. A multi-stage hydraulic fracture design of 13 perforation clusters with 200 -ft spacing ( $z$ to $y$ axis ratio is $1: 10)$. 
The goal of the EGS fracture modeling was to identify the parameters that promote the creation of large, planar fractures in a granitic reservoir with pre-existing natural fractures during hydraulic fracturing operations. We simulated an idealized granitic system using average formation parameters from the published literature for granite. The granite material properties and main reservoir input parameters used are listed in Table 3 and Table 4.

Table 3. Input granite material properties used in the reservoir model (EMI 2010 a, b and Morrell 2012)

\begin{tabular}{|l|l|}
\hline Granite Material Properties \\
\hline Thermal Conductivity $\left(\mathrm{Wm}^{-1} \mathrm{~K}^{-1}\right)$ & 3.15 \\
\hline Porosity $(\%)$ & 0.77 \\
\hline Permeability $(\mu \mathrm{D})$ & 0.5 \\
\hline Young's Modulus $(\mathrm{GPa})$ & 56.9 \\
\hline Poisson's Ratio $(-)$ & 0.32 \\
\hline Total Compressibility $(1 / \mathrm{GPa})$ & 0.43 \\
\hline Tensile Strength $(\mathrm{MPa})$ & 12 \\
\hline Fracture Toughness $\left(\mathrm{MPa} \mathrm{m} \mathrm{m}^{1 / 2}\right)$ & 1.5 \\
\hline
\end{tabular}

Table 4. Default input parameters for fracture simulations (Hu and Tutuncu, 2016)

\begin{tabular}{|l|l|}
\hline \multicolumn{2}{|l|}{ Input Treatment Parameters } \\
\hline Initial Fluid Viscosity (cp) & 160 \\
\hline End Proppant Concentration (PPA) & 4 \\
\hline Pumping Time for Each Stage (min) & 72.43 \\
\hline Maximum Horizontal Stress (psi) & 8,000 \\
\hline Stress Anisotropy (psi) & 0 \\
\hline Rate Per Stage (bbl./min) & 60 \\
\hline
\end{tabular}

We first simulated an ideal reservoir condition where there are no pre-existing natural fractures and stress shadow effects are ignored. The simulation results generated the large planar fracture envisioned in the conceptual EGS design. Fracture half-length for the 13 stages ranging from 600 $\mathrm{ft}$ to $800 \mathrm{ft}$ and fracture widths ranging from 0.05 to 0.5 inches were observed as shown in Figure 16a. The fracture widths near the production well were generally smaller than those near the injection well. After this ideal simulation, we started to add complexities step by step, first by including stress shadow effect in the simulation. In these model results, fractures diverged from adjacent fractures due to stress shadow effects under zero stress anisotropy condition as shown in Figure 16b. 

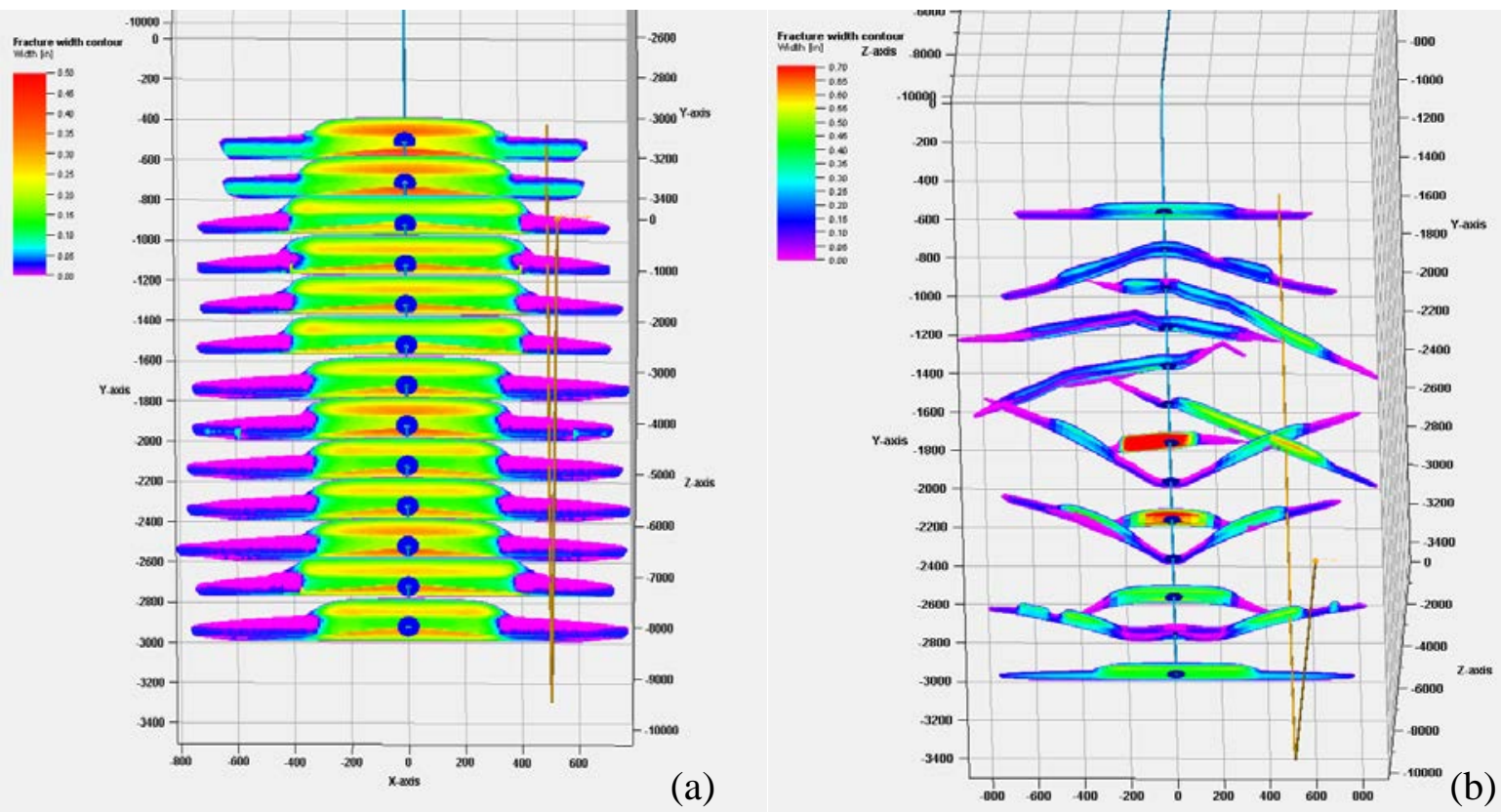

Figure 16. a) Plane top view of simple EGS model consisting of horizontal well with multiple fractures without any natural fractures and stress shadow effect, and b) considering only stress shadow effect.

\section{Complex Fracture Network Simulation}

In the next set of simulations, we employed the Unconventional Fracture Model (UFM) in Mangrove to include the effects of stress shadowing and natural fractures with zero stress anisotropy. In this research study, we used a 2-dimensional (2-D) discrete fracture network (DFN) design simulator to create a randomly distributed natural fracture set with controllable fracture spacing, height, length, and orientation. Figure 17a shows a 2-D DFN consisting of 3,000 natural fractures with a fracture spacing of $60 \pm 15 \mathrm{ft}$. The DFN is made up of a primary natural fracture set consisting of fractures with an average length of $200 \pm 10 \mathrm{ft}$ and oriented $90 \pm$ 15 degrees from the direction of $S_{H m a x}$, and a secondary natural fracture set consisting of fractures with an average length of $150 \pm 10 \mathrm{ft}$ and oriented $0 \pm 15$ degree from the direction of $S_{\text {Hmax. }}$ Using the input parameters in Table 3 and Table 4 and considering the combined effects of stress shadowing and primary and secondary natural fracture networks, we observed a fracture network with a relatively high level of complexity in the simulation results, as shown in Figure 17b. In this simulation, only four stages of the 13 stages propagated far enough to intersect the production well located $500 \mathrm{ft}$ away. Moreover, we observed a significant reduction in the average fracture width due to the fracturing fluid leak-off from hydraulic fractures into natural fractures and preventing proppant placement in the induced fractures. 


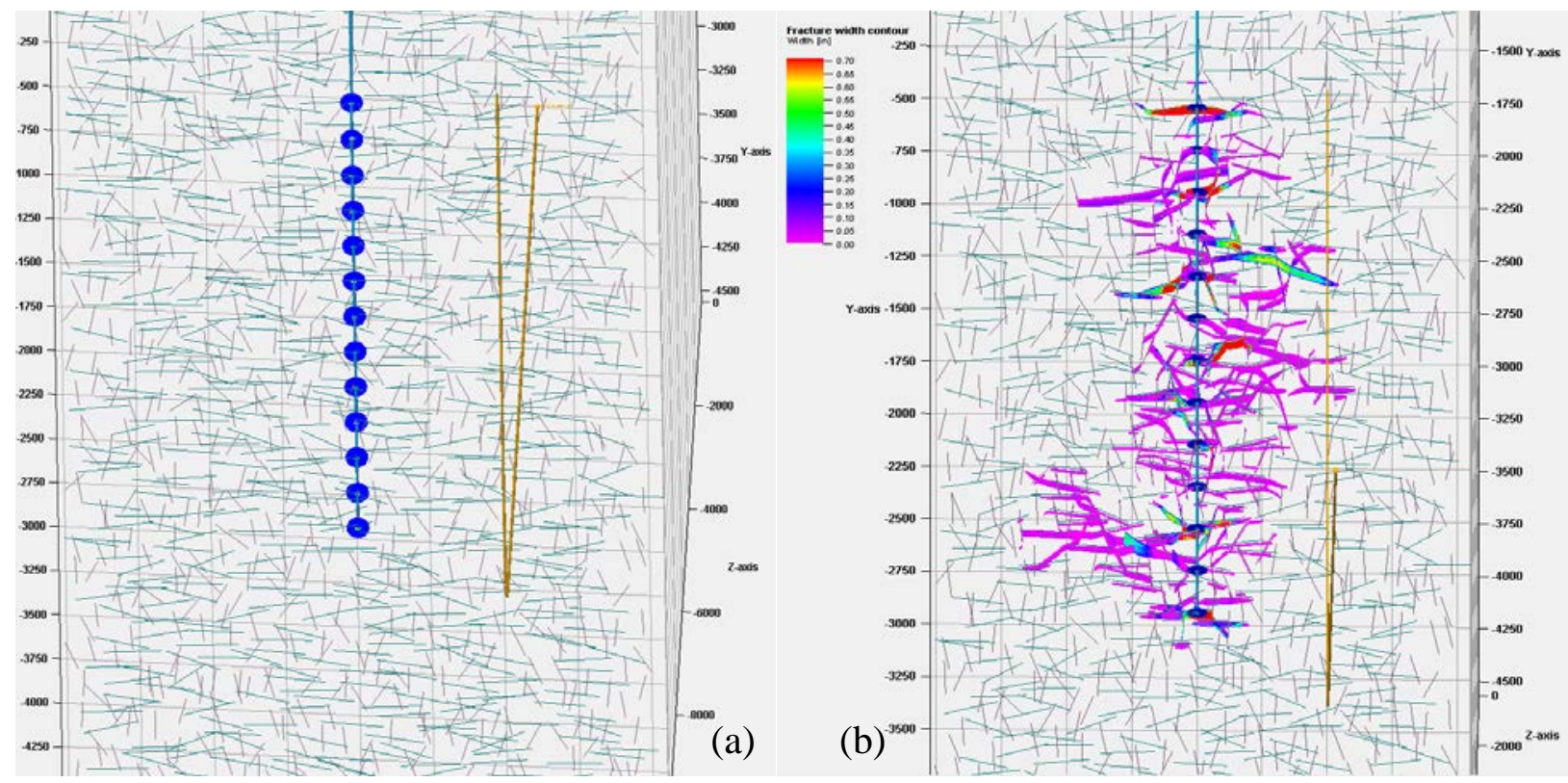

Figure 17. a) Plane top view of simple EGS model consisting of horizontal well with multiple fractures considering natural fractures and b) stress shadow effects.

The horizontal section of the well was constructed (in the simulator) in the direction perpendicular to $S_{H m a x}$. From the observations of the prior simulation results, we noticed that although the stress anisotropy value in the reservoir model was assumed to be zero, under ideal conditions, the induced fracture tended to propagate in the direction of the perforations, which is also the orientation of $S_{\text {Hmax. }}$. However, once the induced hydraulic fractures were affected by stress shadow and intersected with in-situ natural fractures, only a small portion of the induced hydraulic fractures were able to cross the natural fractures and propagate in the original direction because the horizontal minimum stress magnitude $\left(\mathrm{S}_{H \min }\right)$ is identical to $\mathrm{S}_{H \max }$ magnitude. Most of the induced fractures tended to either diverge from adjacent fractures or merge into natural fractures and eventually arrest inside the natural fractures in a direction different from the orientation of $S_{H \max }$. Running simulation cases with various DFN orientations, we noticed that when most of the natural fractures were in the direction perpendicular to $S_{H \max }$, the induced hydraulic fractures were initially able to cross the first several natural fractures; but eventually, they stopped or merge into natural fractures due to the large friction losses while crossing the natural fractures. However, when most of the natural fractures were in the direction parallel to SHmax, natural fractures behaved as pre-opened hydraulic fractures, and they therefore aided the creation of large planar fractures. When most of the natural fractures were orientated between the $S_{H \max }$ and $\mathrm{S}_{\mathrm{Hmin}}$ directions, most induced hydraulic fractures tended to merge into the natural fractures.

The above simulations were carried out assuming zero stress anisotropy. Therefore, we performed another set of simulations assuming a stress anisotropy of 500 psi, both without and with a natural fracture network. Stress shadow effects were included in both simulations. Simulation results for the two cases are shown in Figure 18. Without a natural fracture network, the large stress anisotropy applied nearly eliminated the effects of stress shadowing as shown in Figure 18a. 

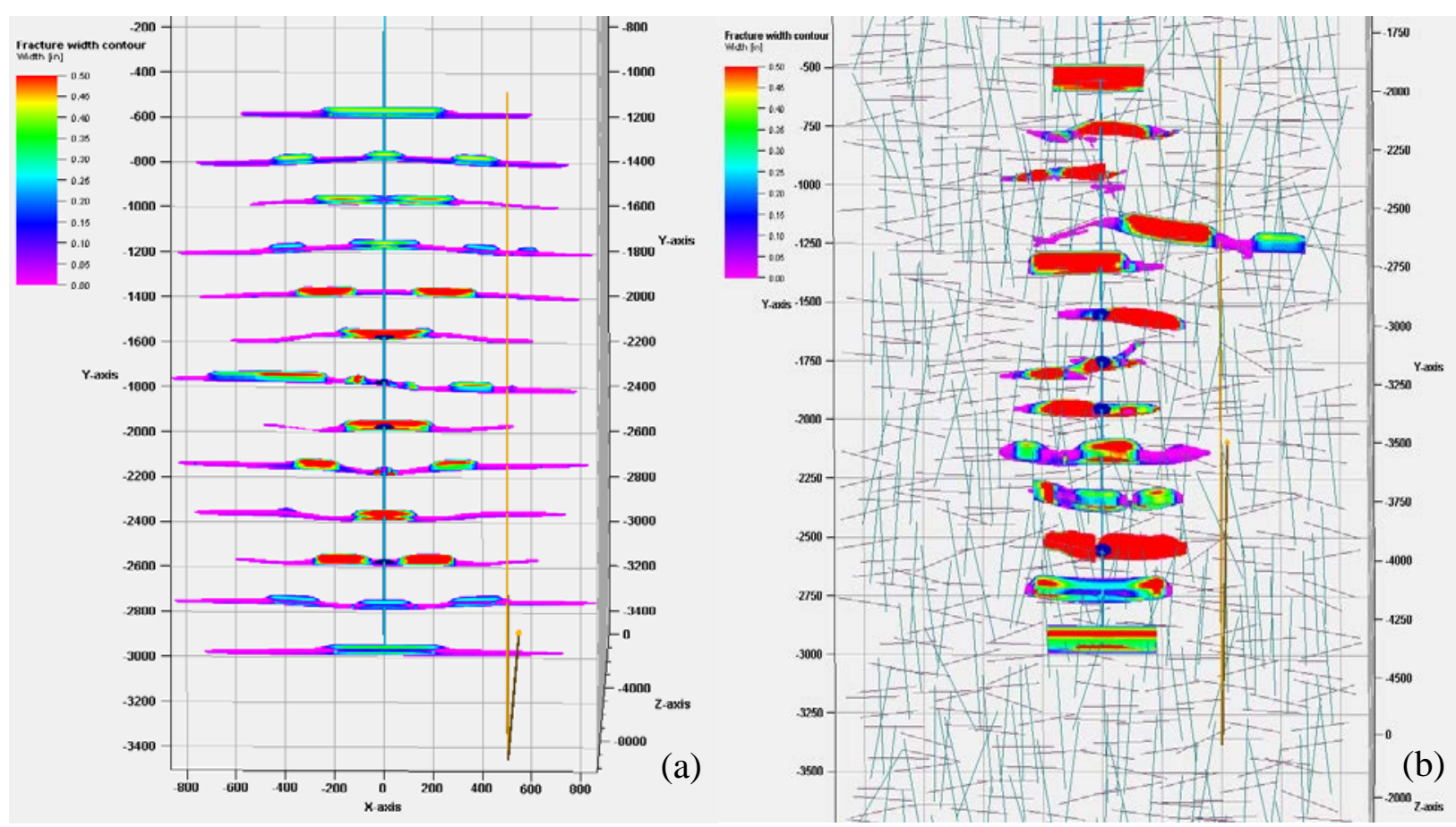

Figure 18. Top view of simulations consisting of horizontal well with multiple fractures assuming stress anisotropy of $\mathbf{5 0 0}$ psi a) without natural fractures, and b) with natural fractures.

Figure 18b shows that the level of complexity for the created fracture network is also significantly reduced by increasing stress anisotropy in the reservoir even when a DFN is included. Only one stage was able to achieve the desired fracture half-length, whereas the other stages were arrested due to large friction losses from crossing the densely distributed natural fractures. Additionally, more proppant was properly placed inside the induced fractures than in the zero-anisotropy case. This resulted in an increase in the average fracture widths, as illustrated in the fracture width contours in Figure 18b. Hydraulic fractures for most stages had an average fracture width exceeding 0.5 inch.

\section{Sensitivity Analysis}

We performed a sensitivity analysis to determine which simulation parameters have the greatest impact on fracture complexity. Simulations were performed to explore the relative impact of simulation parameters and assumptions, illustrated conceptually by the matrix in Table 5.

Table 5. Schematic matrix of simulations under EGS model in investigating effects of various parameters on fracture network complexity

\begin{tabular}{|l|l|l|l|l|}
\hline \multirow{2}{*}{$\begin{array}{l}\text { Ideal } \\
\begin{array}{l}\text { Condition } \\
\text { without NF }\end{array}\end{array}$} & Stress State & Fluid Viscosity & $\begin{array}{l}\text { Proppant } \\
\text { Concentration }\end{array}$ & Pump Rate \\
\cline { 2 - 5 } & $\begin{array}{l}\text { Various Stress } \\
\text { Anisotropy }\end{array}$ & $\begin{array}{l}\text { Water vs. Low } \\
\text { Concentration vs. } \\
\text { High Concentration }\end{array}$ & $\begin{array}{l}\text { Zero vs. Low } \\
\text { Concentration vs. } \\
\text { High Concentration }\end{array}$ & $\begin{array}{l}\text { High Pump } \\
\text { Rate vs. Low } \\
\text { Pump Rate }\end{array}$ \\
\hline $\begin{array}{l}\text { Pre-Existing } \\
\text { Natural } \\
\text { Fracture }\end{array}$ & $\begin{array}{l}\text { Effects of Various NF } \\
\text { Orientation, Density, } \\
\text { and Fracture Spacing }\end{array}$ & $\begin{array}{l}\text { Water vs. Low } \\
\text { Concentration vs. } \\
\text { High Concentration }\end{array}$ & $\begin{array}{l}\text { Zero vs. Low } \\
\text { Concentration vs. } \\
\text { High Concentration }\end{array}$ & $\begin{array}{l}\text { High Pump } \\
\text { Rate vs. Low } \\
\text { Pump Rate }\end{array}$ \\
\hline
\end{tabular}


Based on results from the matrix simulations, the five parameters with the most noticeable impact on fracture network complexity were DFN spacing, fluid viscosity, stress anisotropy, pump rate, and proppant concentration. The original input parameters relative to the parameters used in the sensitivity analysis parameters are shown in Table 7 . The relative impact on the simulation results is shown in Figure 19 to Figure 21. The numbers in parentheses in the figures show the range parameter values used. Parameters are ordered in terms of significance of their overall impact on the fracture half-length, average fracture width, and effective fracture conductivity.

Table 6. Comparison of the input parameters used in base case and range of input parameters used in the sensitivity analysis through simulations

\begin{tabular}{|l|l|l|}
\hline Property & Original Input Parameters & $\begin{array}{l}\text { Sensitivity Analysis } \\
\text { Parameters }\end{array}$ \\
\hline DFN Spacing (ft) & 60 & $60-200$ \\
\hline Fluid Viscosity (cp) & 160 & $0.64-200$ \\
\hline End Proppant Concentration (PPA) & 4 & $1-8$ \\
\hline Stress Anisotropy Value (psi) & 0 & $0-500$ \\
\hline Pump rate (bbl/min) & 60 & $15-90$ \\
\hline
\end{tabular}

Proppant concentration had the greatest impact on the average fracture width, followed by the fluid viscosity and pump rate as shown in Figure 19. This is expected because a large pump rate, high fluid viscosity, and high proppant concentration should aid in placing proppant in the fractures and creating wider fractures. Stress anisotropy and DFN spacing tend to have less of an impact. The ranking of relative influence on fracture connectivity (Figure 20) was found to be exactly the same as for fracture width because effective conductivity tends to have a linear relationship with average fracture width. For the effect in fracture half-length (shown in Figure 21), DFN spacing was determined to be the most significant parameter, followed by fluid viscosity and stress anisotropy. Due to the fixed proppant increment setting inside the UFM model simulation, as proppant concentration increases, the total pumping volume also increases, which is the main contributing factor for adding growth in the fracture half-length. The sensitivity analysis indicated that the pump rate is the least significant contributing factor to fracture half-length. 


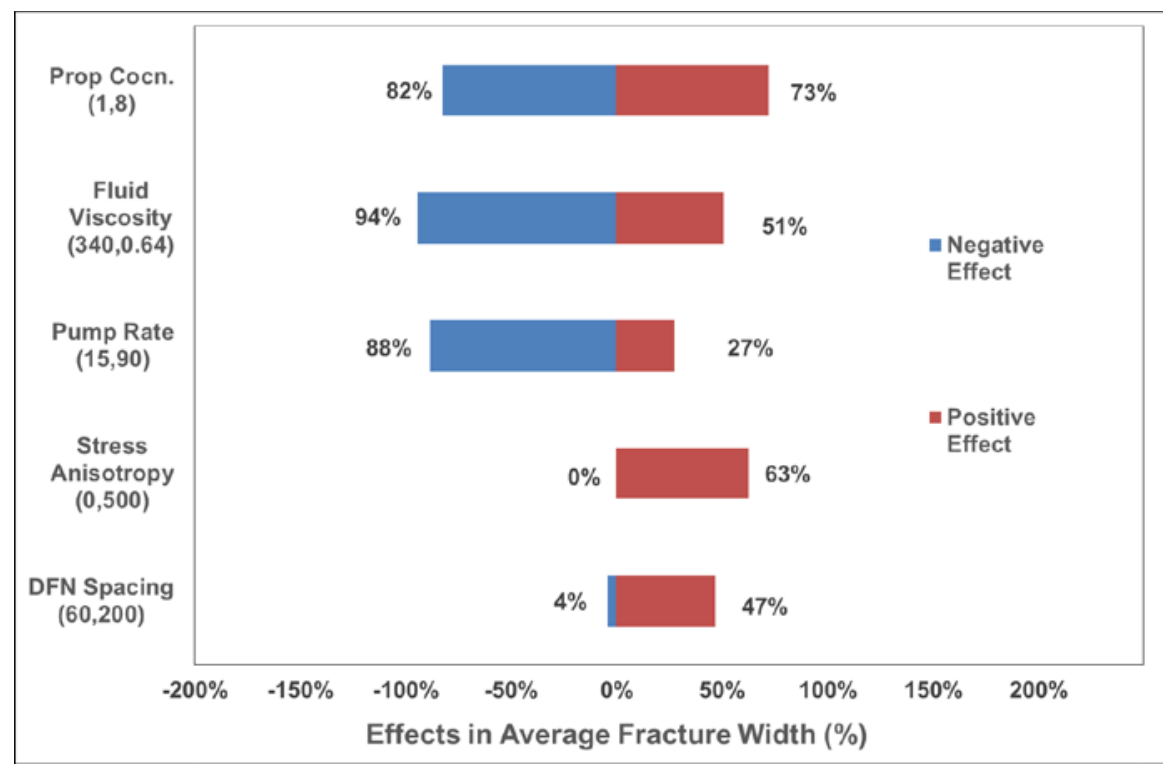

Figure 19. Sensitivity effect of parameters in average fracture width.

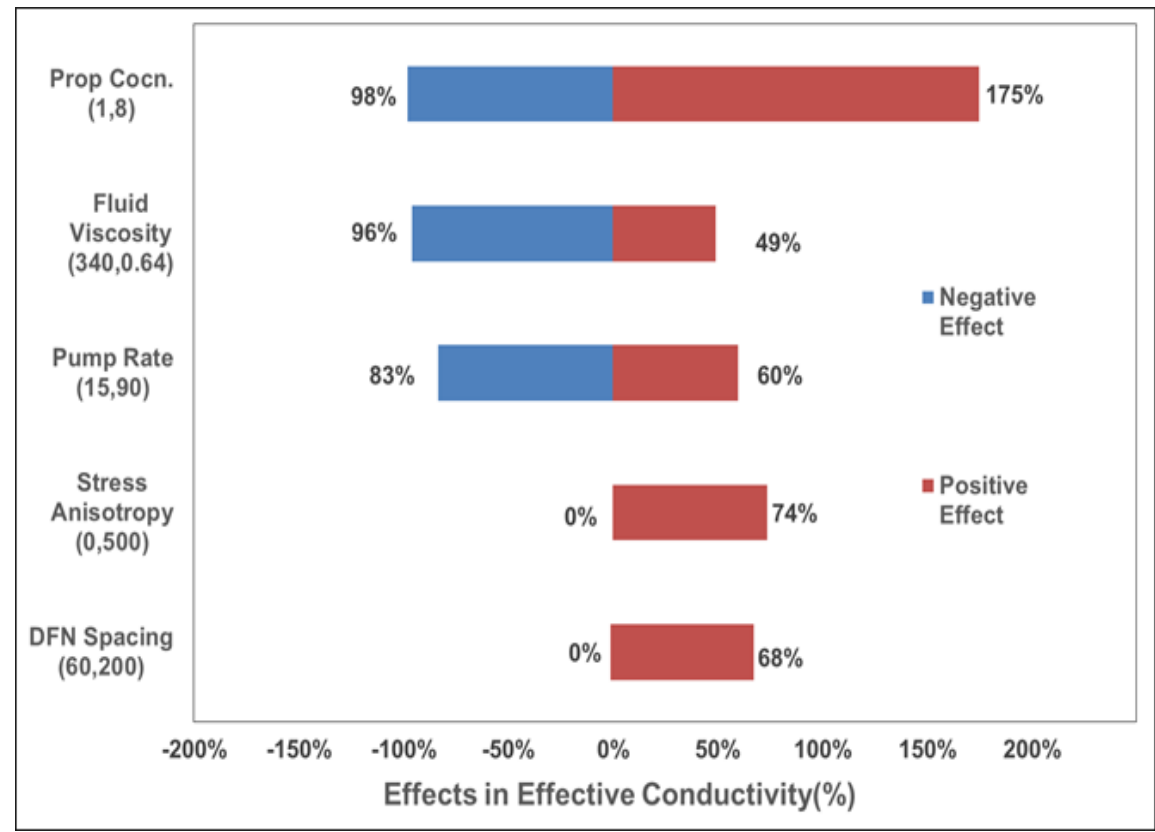

Figure 20. Sensitivity effect of parameters on effective conductivity 


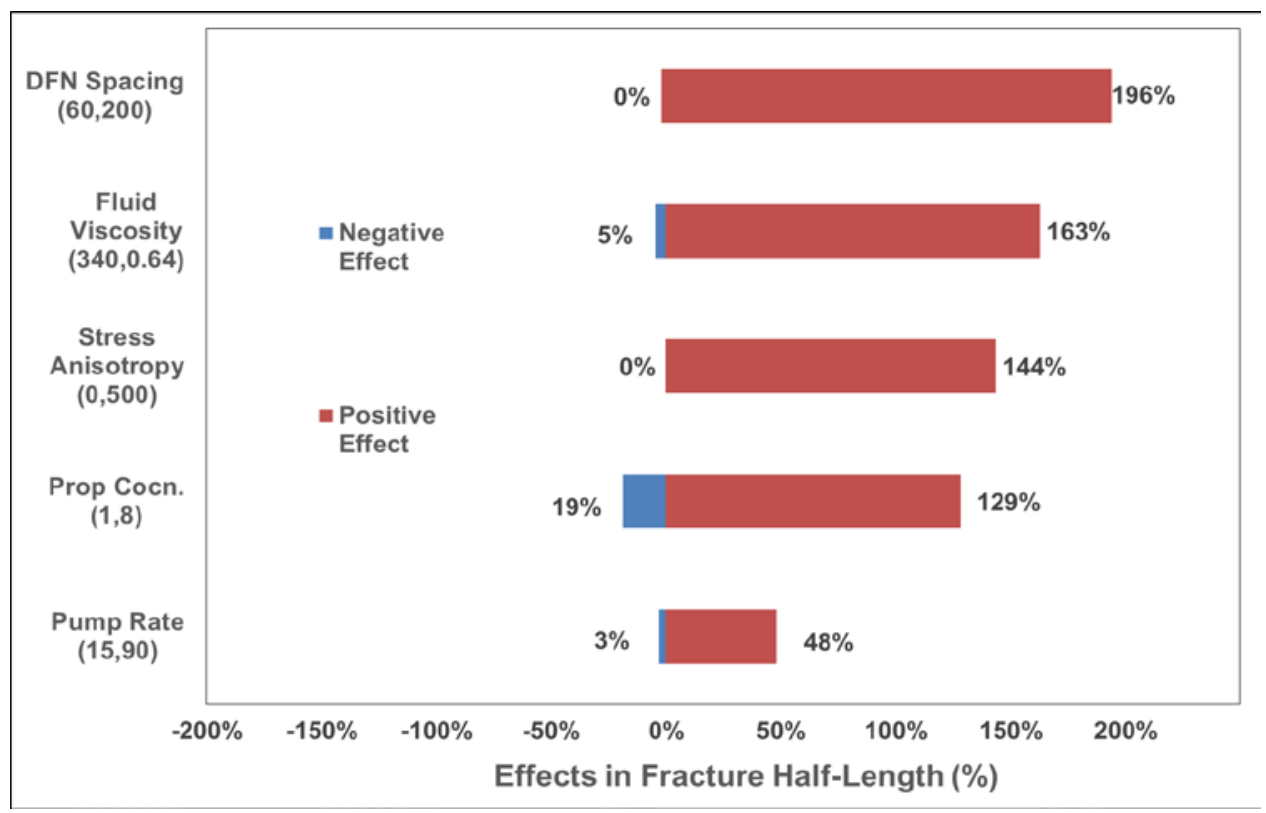

Figure 21. Sensitivity effect on fracture half-length.

\section{Design Optimization}

After obtaining the results from the sensitivity analysis, we performed an "optimum-case" simulation. This optimum-case simulation combined the simulation reservoir settings and parameters that had the most positive effects on creating large planar fractures (i.e., minimized fracture complexity): a natural fracture network aligned with SHmax $_{\text {; large reservoir stress }}$ anisotropy; relatively large natural fracture spacing; and parameters with values that had the most positive effects in the sensitivity analysis. The DFN design parameters used in the simulations under the optimum-case scenario are illustrated in Table 7, and the treatment parameters are shown in Table 8.

Table 7. 2-D DFN design parameters for optimization while considering positive effects of relatively large NF spacing of $120 \mathrm{ft}$ in the model simulation

\begin{tabular}{|l|l|l|l|l|l|l|l|}
\hline \multirow{2}{*}{$\begin{array}{l}\text { Natural } \\
\text { Fracture } \\
\text { Set }\end{array}$} & \multirow{2}{*}{$\begin{array}{l}\text { Number } \\
\text { of } \\
\text { Fractures }\end{array}$} & \multicolumn{2}{|l|}{ Length $(\mathrm{ft})$} & \multicolumn{2}{l|}{ Spacing (ft) } & \multicolumn{2}{l|}{ Orientation (degree) } \\
\cline { 3 - 8 } & Average & $\begin{array}{l}\text { Standard } \\
\text { Deviation }\end{array}$ & Average & $\begin{array}{l}\text { Standard } \\
\text { Deviation }\end{array}$ & Average & $\begin{array}{l}\text { Standard } \\
\text { Deviation }\end{array}$ \\
\hline Primary & 2,000 & 200 & 10 & 120 & 10 & 90 & 15 \\
\hline Secondary & 1,000 & 150 & 10 & 120 & 10 & 0 & 15 \\
\hline
\end{tabular}


Table 8. Treatment parameters for design optimization with positive reservoir condition in achieving successful EGS application in the model simulation

\begin{tabular}{|l|l|}
\hline Simulation Case & Design Optimization \\
\hline Initial Fluid Viscosity (cp) & 340 \\
\hline End Proppant Concentration (PPA) & 8 \\
\hline Rate Per Stage (bbl/min) & 90 \\
\hline Pumping Time for Each Stage (min) & 200 \\
\hline Total Slurry Volume (bbl) & 18,032 \\
\hline Total Proppant Mass (lb) & $2,640,000$ \\
\hline Total Fluid Volume (gal) & 660,000 \\
\hline Stress Anisotropy (psi) & 500 \\
\hline
\end{tabular}

A 3-dimensional (3-D) view and top view of the simulated fracture network geometries for the EGS design optimization are shown in Figure 22. The numerical results for the fracture halflength, average fracture width, and effective conductivity of each stage in Figure 22 are listed in Table 9. In summary, the average fracture half-length for all 13 stages is $549 \mathrm{ft}$, the average fracture width for all thirteen stages is 1.25 inches, and the average effective fracture conductivity for all 13 stages is 707,668 md-ft. It should be noted that the simulation results for Figure 22 were based on a symmetrical completion sequence, where the odd-number stages were stimulated first (from toe to heel), followed by the even-number stages. This is not practical in actual field operations, so we performed one more simulation with a conventional sequential completion from the toe to the heel of the well as shown in Figure 23a. Another similar simulation with the conventional completion sequence was performed with a reduction in the average length of the natural fractures as shown in Figure 23b. 

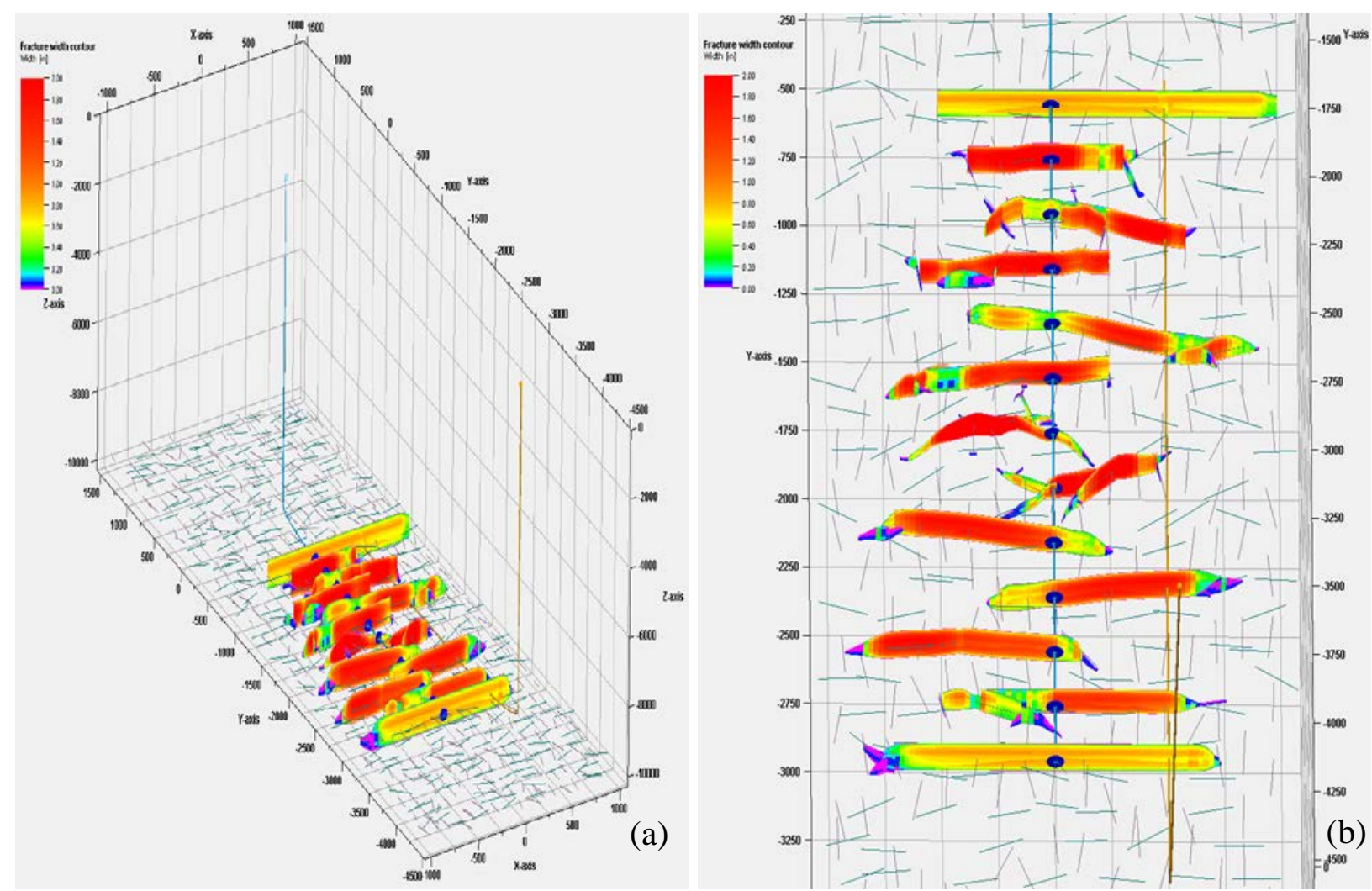

Figure 22. 3-D view (a) and top view (b) of EGS design optimization with symmetrical completion order ( $y$ to $z$ ratio is $5: 1$ ).

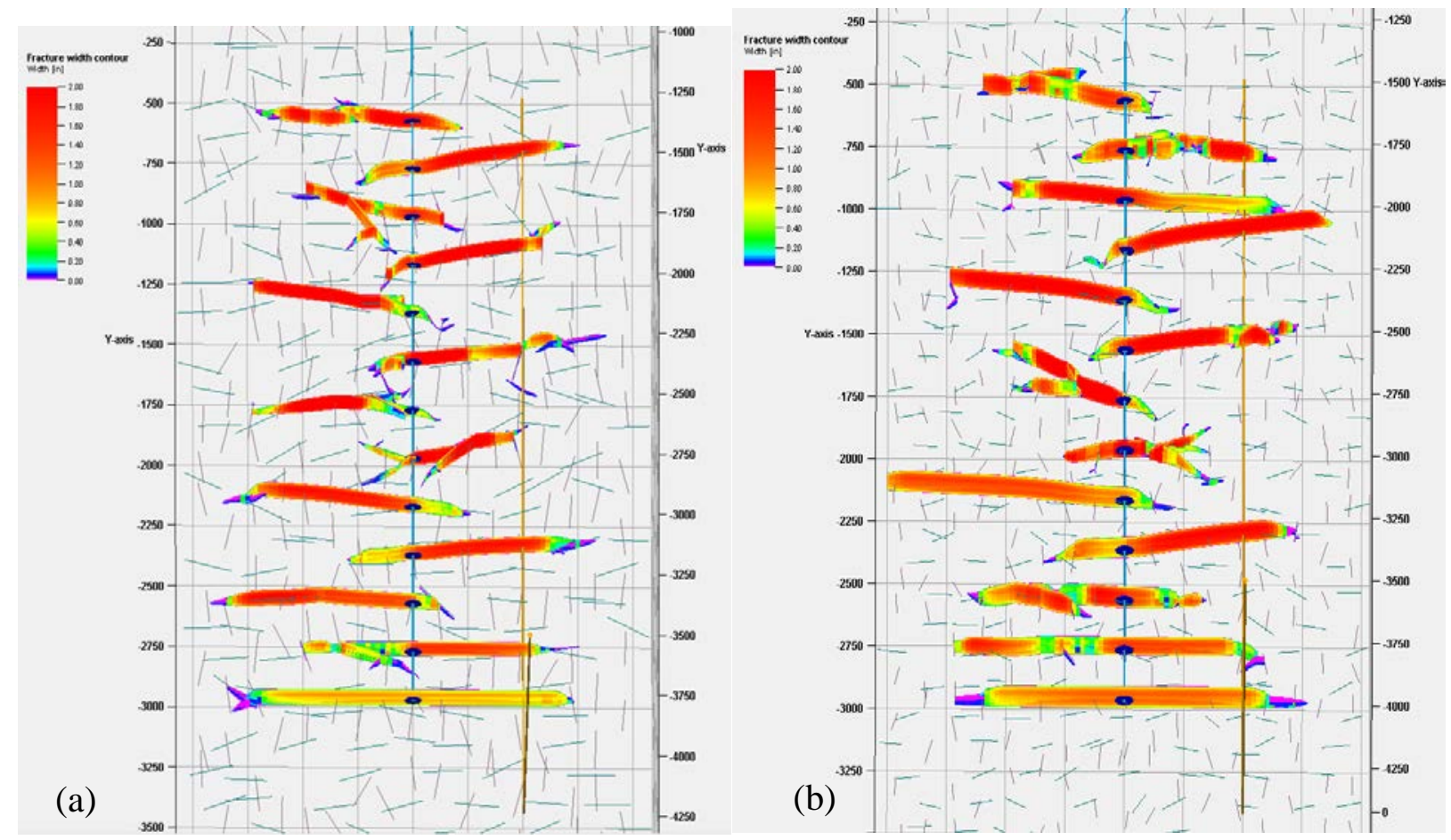

Figure 23. Top view of EGS design optimization with sequential completion order while considering both the positive and negative effects of (a) complex reservoir condition and reduced (b) NF length. 
Using the coupled geomechanics and fluid flow (UFM) model and considering the negative and positive effects of reservoir and treatment parameters, we were able to simulate an EGS-type large planar fracture network with a very low level of complexity while obtaining desirable fracture half-length and large average fracture width. Reservoirs with high stress anisotropy were found to reduce stress shadow effects that cause fractures to diverge from their initial fracture pathways. As Figure 22 shows, most fractures tend to propagate in the direction of maximum horizontal stress. Although the stress shadow can still affect the overall fracture half-length, as observed in stages 2 to 12. Once an unsymmetrical fracture is generated due to friction loss when crossing natural fractures, fractures from the adjacent stage tend to propagate in the opposite direction from the fractures in the previous stage, which results in a "natural zipper pattern" from the single injection well. However, by using different fracture patterns and/or larger fracture spacing, the effects of stress shadowing could be reduced.

Table 9. Simulated numerical results for each stage regarding fracture half-length, average fracture width, and effective conductivity for model simulation in Figure 22. Simulation run using parameters from Table 8.

\begin{tabular}{|l|l|l|l|}
\hline Stage & $\begin{array}{l}\text { Fracture Half-Length } \\
\text { (ft) }\end{array}$ & $\begin{array}{l}\text { Average Fracture Width } \\
\text { (in.) }\end{array}$ & $\begin{array}{l}\text { Effective Fracture Conductivity } \\
\text { (md-ft) }\end{array}$ \\
\hline 1 & 790 & 0.82 & 478,468 \\
\hline 2 & 628 & 1.1 & 562,886 \\
\hline 3 & 553 & 1.3 & 704,428 \\
\hline 4 & 563 & 1.23 & 693,448 \\
\hline 5 & 562 & 1.26 & 718,556 \\
\hline 6 & 383 & 1.45 & 794,198 \\
\hline 7 & 427 & 1.83 & 916,130 \\
\hline 8 & 496 & 1.34 & 883,060 \\
\hline 9 & 642 & 1.05 & 490,323 \\
\hline 10 & 449 & 1.39 & $1,032,015$ \\
\hline 11 & 468 & 1.13 & 569,544 \\
\hline 12 & 425 & 1.51 & 897,308 \\
\hline 13 & 745 & 0.9 & 459,280 \\
\hline Average & 549 & 1.25 & 707,665 \\
\hline
\end{tabular}




\section{Results}

Using a coupled geomechanics and fluid flow model, we were able to 1) observe the basic behavior of complex fracture network creation such as the effects of stress shadowing and preexisting natural fracture networks, and 2) identify the reservoir and fracture treatment parameters that minimize fracture complexity and promote the creation of large planar fractures. The 2-D DFN model enabled us to design pre-existing natural fractures with variable orientations, lengths, and spacing and explore their positive and negative effects on the fracture network complexity. When natural fractures are aligned with $\mathrm{S}_{\mathrm{Hmax}}$, hydraulic fractures tend to propagate further into the formation, aiding the creation of simple, planar-shaped fractures. When the natural fractures are not aligned in the direction of $S_{H \max }$, the natural fractures behave like barriers to the hydraulic fractures, forcing the hydraulic fractures to either arrest in the natural fractures, or cross over them resulting in friction losses. Results for the matrix simulation and sensitivity analysis indicate that the hydraulic fracture network complexity can be minimized by 1) selecting reservoirs with large stress anisotropy, and natural fracture networks that have large DFN spacing and favorable orientation with S Smax, and 2) choosing fracture treatment parameters such as high viscosity fluid, a relatively high proppant concentration, and high pump rate. 


\section{Conclusions}

We investigated technology and operational techniques that can be adapted from the oil and gas industry's success in horizontal wellbore placement and multistage stimulation to the completion of horizontal geothermal wells for creating enhanced geothermal systems. We proposed well designs for horizontal injection and production. The designs assumed a reservoir temperature of $200^{\circ} \mathrm{C}\left(392^{\circ} \mathrm{F}\right)$, production well flow rates of 43,500 barrels per day $(80 \mathrm{~kg} / \mathrm{s})$, and an injection well flow rate of 87,000 barrels per day (160 kg/s). Our analysis found that a 9-5/8” $53.5 \mathrm{ppf}$ P110 casing string meets all design criteria for the horizontal section of injection and production wells. A P110 grade is common and is often used in horizontal sections of shale development wells in petroleum operations. Our study found that casing connections may be a weak point in the design and that non-API premium casing connections should be considered.

We recommended two production-well completions techniques: plug-and-perf and port-andpacker completions. The plug-and-perf technique would likely present the least technical risk but would also be the most expensive option. A port-and-packer system would likely be the simplest and fastest to implement from a technical standpoint and has several other advantages, such as avoiding the need to cement the casing in the horizontal section in place. However, the ability of external packers to adequately isolate sections could be problematic due to the difficulty of forming a seal between the outside of the casing and the rough walls of the open borehole. For all techniques considered, temperature limitations of equipment are a concern. Commercially available equipment designed to operate at high temperatures encountered in geothermal systems is available, but it is generally unproven for geothermal applications. However, we did not identify any major "showstoppers." Based on our study, we believe that further evaluation is warranted of adapting oil and gas completion techniques to EGS.

The Mangrove UFM model was found to be an effective model capable of capturing the basic characteristics of complex reservoir conditions such as stress shadow effects and pre-existing natural fracture geometry and fracture propagating prediction when compared with a conventional type of Cartesian grid structured simulator.

The 2-D DFN design under the UFM model enabled users to artificially design pre-existing natural fractures with desirable orientation, length, and space under the circumstance where seismic data are not valid, and to investigate positive and negative effects of natural fractures toward fracture network complexity. If natural fractures are in the same direction as $\mathrm{SH}_{\max }$, the inclusion of DFN helps hydraulic fractures to propagate farther into the formation, which enables the desired simple, planar-shaped fractures. If the natural fractures are not in the direction of $\mathrm{SH}_{\max }$, the DFN behaves like barriers to hydraulic fractures, forcing the hydraulic fractures to either merge into the natural fracture, or actually cross over them, which results in more friction loss while pumping fluid.

We considered only stress anisotropy and stress shadow effects from adjacent fracture stages during hydraulic fracturing treatment regarding in-situ stress changes; we did not model stressstate alteration induced from those pre-existing NFs at this time. However, simulations under the UFM model did provide a reasonable and logical sample of prediction and analysis in optimum EGS design, and the prediction would become more accurate as more real field data are integrated after actual field application. The matrix of simulation and sensitivity analysis results 
indicate that the hydraulic fracture network complexity can be overcome or reduced to a minimum level. For reservoirs with properties conducive to planar fracture growth, such as large stress anisotropy and larger DFN spacing with "friendly" orientation, successful creation of enhanced geothermal systems can be accomplished by using optimum treatment parameters such as large pumping volume of high-viscosity fluid with a relatively high proppant concentration and high pump rate.

Also, we identified stress shadow effects as another significant impact in creating complex fracture geometry, even under the condition where stress anisotropy is sufficiently large to force most fractures to propagate in the desired direction. In our optimum design for EGS applications, we only considered a simple fracture pattern: from stages 1 to 6 , and from stages 13 to 8 , and then finally, stage 7 , which creates a symmetrical fracture network. We can more effectively reduce the stress shadow effects by applying an engineering-designed zipper pattern and modified zipper pattern. 


\section{Related Publications from Study}

- Stanford Geothermal Workshop Palo Alto, CA; Jan. 26-28, 2015

o SGP-TR-204, Design Considerations for Applying Multi-Zonal Isolation Techniques in Horizontal Wells in a Geothermal Setting, J. Olson, C. Augustine, A. Eustes, W. Fleckenstein

- GRC 2015; Reno, NV; Sept. 21-23, 2015

o Completion Design Considerations for a Horizontal Enhanced Geothermal System, J. Olson, A. Eustes, W. Fleckenstein, E. Eker, R. Baker, C. Augustine

- ARMA 2016; Houston, TX; June 26-29, 2016

o Use of Coupled Geomechanics and Fluid Flow Model for Optimization of Multistage Hydraulic Fracturing and Horizontal Wells in Enhanced Geothermal System Applications, X. Hu, A. Tutuncu

- GRC 2016; Sacramento, CA; Oct. 23-26, 2016

o Casing Design Finite Element Model Under Geothermal Cycling, R. Baker, A. Eustes, A. Tutuncu, C. Augustine

o Optimizing for Large Planar Fractures in Multistage Horizontal Wells in Enhanced Geothermal Systems Using a Coupled Fluid and Geomechanics Simulator, X. Hu, A.N. Tutuncu, A. Eustes, C. Augustine 


\section{References}

[1] A. C. Gringarten, P. A. Witherspoon, and Y. Ohnishi, (1975). Theory of Heat Extraction from Fractured Hot Dry Rock. Journal of Geophysical Research, Volume 80, No. 8, pp 1120-1124.

[2] B. Alp and S. Akin, (2013). Utilization of Supplementary Cementitious Materials in Geothermal Well Cementing. Turkish Petroleum Corporation Research Center, Cankaya, Ankara, Turkey.

[3] B. D. Craig and L. Smith, (2011). Corrosion Resistant Alloys (CRAs) in the Oil and Gas Industry. Nickel Institute, Nickel Institute Technical Series No. 10073.

[4] B. Edment, F. Elliott, J. Gilchrist, B. Powers, R. Jansen, T. McPike, H. Onswusiri, M. Parlar, A. Twynam, and A. van Kranenburg, (2005). Improvements in Horizontal Gravel Packing. Oilfield Review, Spring 2005, pp. 50-60.

[5] C. Holt, N. Lahoti, and V. Fortier, (2013). New Cementing Method Uses Pipe Movement to Maximize Displacement. http://www.drillingcontractor.org/new-cementing-methoduses-pipe-movement-to-maximize-displacement-21248. Drilling Contractor, Innovation While Drilling, March/April 2013.

[6] C. Teodoriu and G. Falcone, (2008). Comparing Completion Design in Hydrocarbon and Geothermal Wells: The Need to Evaluate the Integrity of Casing Connections Subject to Thermal Stresses. Department of Petroleum Engineering, Texas A\&M University, 3116 TAMU, ge Station, TX, USA.

[7] D. Duchane and D. Brown, (2002). Hot Dry Rock (HDR) Geothermal Energy Research and Development at Fenton Hill, New Mexico. Los Alamos National Laboratory Associates, Los Alamos, NM, USA.

[8] T. Doe, R. McLaren, and W. Dershowitz, (2014). Discrete Fracture Network Simulations of Enhanced Geothermal Systems. Proc. $39^{\text {th }}$ Workshop on Geothermal Reservoir Engineering. Stanford University.

[9] T. Doe, R. McLaren, and W. Dershowitz, (2014). Discrete Fracture Network Simulations of Enhanced Geothermal Systems. Proc. $39^{\text {th }}$ Workshop on Geothermal Reservoir Engineering. Stanford University.

[10] E. Gollmyer, S. Mitchell, A. Bailey, B. Rickard, and S. Pye, (2011). Casing Protection for Geothermal Wells. WWT International Inc. and Geothermal Resource Group Inc., GRC Transactions, Volume 35, pp. 165-168.

[11] EMI, (2010). Orica-4_BTS. Brazilian Tensile Strength Test Datasheet for Orica Core ID 4, Colorado School of Mines Earth Mechanics Institute, Oct. 6. 167.

[12] EMI, (2010). Orica-4_BTS. Brazilian Tensile Strength Test Datasheet for Orica Core ID 4, Colorado School of Mines Earth Mechanics Institute, Oct. 6. 167.

[13] E. Peza, E. Kvale, R. Hand, W. Harper, R. Jaykumar, D. Wood, E. Wigger, B. Dean, Z. Al-Jalal, and S. Ganpule. How Fracture Interference Impacts Woodford Shale Gas Production. World Oil, p. 10-14, March 2015.

[14] G. Trabits and E. Hass, (2013). Development of an Improved Cement for Geothermal Wells. U.S. Department of Energy Peer Review, Denver, CO.

[15] GEODynamics, (2007). General Data on Explosives. http://www.peregrinempllc.com/uploads/product_info/information/geo_explosives_info.p df. GEODynamics, Millsap, TX. 
[16] GEODynamics, (2013). GEODynamics Technical Catalog 2013.

http://perf.com/catalogs/Geodynamics-2013-Summer-Catalog.pdf. GEODynamics, Millsap, TX.

[17] W. A. Gringarten, A. P. Witherspoon, and Y. Ohnishi, (1975). Theory of Heat Extraction from Hot Dry Rock. J. Geophysical Research, Volume 80, pp. 1120 -1124.

[18] Halliburton, (2005). Foam Cement Delivers Long-Term Zonal Isolation and Decrease Remedial Costs. http://www.halliburton.com/public/cem/contents/data_sheets/web/h/h02656-a4.pdf. Halliburton Cementing, October, 2005.

[19] Halliburton, (2006). - ThermaLockTM Cement. http://www.halliburton.com/public/cem/contents/Data_Sheets/web/H/H01458_Thermalo ck.pdf. Halliburton Cementing, April, 2006

[20] Halliburton, (2012). Halliburton Cased Hole Test Tools.

http://www.halliburton.com/public/ts/contents/Books_and_Catalogs/web/TestTools/05_D ownhole\%20Tools.pdf.

[21] Halliburton, (2014). Halliburton - Cementing - Cement Blends - ThermaLock. http://www.halliburton.com/en-US/ps/cementing/materials-chemicals-additives/cementblends/thermalock-cement.page\#.

[22] H. Hannes, T. Babadagli, and G. Zimmermann, (2013). Numerical Simulation of Complex Fracture Network Development by Hydraulic Fracturing in Naturally Fractured Ultra Tight Formations, Proc. ASME $32^{\text {nd }}$ International Conference on Ocean, Offshore and Arctic Engineering.

[23] X. Hu and A. N. Tutuncu, (2016). Use of Coupled Geomechanics and Fluid Flow Model for Optimization of Multistage Hydraulic Fracturing and Horizontal Wells in Enhanced Geothermal System Applications, ARMA 16-428, Proceedings of the $50^{\text {th }}$ US Rock Mechanics/Geomechanics Symposium.

[24] X. Hu, A. Tutuncu, A. Eustes, and C. Augustine, (2016). Optimizing for Large Planar Fractures in Multistage Horizontal Wells in Enhanced Geothermal Systems using a Coupled Fluid and Geomechanics Simulator, Geothermal Resources Council Annual Meeting, Sacramento, California; October 24-26, 2016.

[25] X. Hu, (2016). A Coupled Geomechanics And Flow Modeling Study For Multistage Hydraulic Fracturing Of Horizontal Wells In Enhanced Geothermal Systems Applications. Thesis MSPE Colorado School of Mines.

[26] J. C. Castaneda, L. Castro, and S. Craig, (2010). Sand Plugs Isolate Frac Stages in Barnett Shale. http://www.epmag.com/Technology-Equipment/Sand-plugs-isolate-fracstages-Barnett-well_69428. E\&P, Hart Energy, Houston, TX.

[27] J. Finger and D. Blankenship, (2010). Handbook of Best Practices for Geothermal Drilling. Sandia National Laboratories, Albuquerque, New Mexico.

[28] J. Olson, A. Eustes, W. Fleckenstein, E. Eker, R. Baker, and C. Augustine, (2015). Completion Design Considerations for a Horizontal Enhanced Geothermal System, GRC Transactions, v. 39, p. 335-344.

[29] K. Niggeman, A. Samuel, A. Morris V, and R. Hernandez, (Date Unknown). Foamed Cementing Geothermal 13 3/8-in. Intermediate Casing: NGP \#61-22. Nevada Geothermal Power, Geothermal Resource Group, and Halliburton.

[30] K. Svatek, (2014). 3D Grid Oriented Hydraulic Fracture Simulator; What is GOHFER ${ }^{\circledR}$. http://gohfer.com/what-is-gohfer.html, Barree \& Associates LLC. 
[31] T. Jacobs, (2017), Oil and Gas Producers Find Frac Hits in Shale Wells a Major Challenge. Journal of Petroleum Technologies, Volume 69, Issue 4.

https://www.spe.org/en/jpt/jpt-article-detail/?art=2819

[32] R. Morrell, (2012), Thermal Expansion. National Physical Laboratory. Accessed on 9/28/12 at http://www.kayelaby.npl.co.uk.

[33] New Energy and Fuel, (2012). Get Ready for Super Fracking! http://newenergyandfuel.com/http:/newenergyandfuel/com/2012/01/16/get-ready-forsuper-fracking/.

[34] P. Mathur and N. Kumar, (2013). Contrast Between Plug and Perf and Ball and Sleeve Method for Horizontal Well Stimulation. Pandit Deendayal Petroleum University, Gandhinagar, Gujarat, India.

[35] Packers Plus, (2014). High Temperature Geothermal Well Completed with Inferno Tools; Cooper Basin, Australia.

http://www.packersplus.com/media/casestudies/INT/PP_CS_Cooper_Basin_AustraliaInferno_INT.pdf. Packers Plus Energy Services Inc. Case Study, 2014.

[36] Packers Plus, (2014). StackFRAC HS Multi-Stage Completion System. http://www.packersplus.com/media/brochures/2014/PP-BRO-StackFRACHD-Web-14JUL-2014.pdf.

[37] R. Nurmi, (1995). Horizontal Highlights. Middle East Well Evaluation Review, No. 16.

[38] A. Riahi, B. Damjanac, and J. Furtney, (2014). Discrete Element Modeling of ThermoHydro-Mechanical Coupling in Enhanced Geothermal Reservoirs. Thirty-Ninth Workshop on Geothermal Reservoir Engineering. Stanford University, CA, Stanford Geothermal Program.

[39] S. A. Bernal, R. Mejia de Gutierrez, J. L. Provis, and V. Rose, (2010). Effect of Silicate Modulus and Metakaolin Incorporation on the Carbonation of Alkali Silicate-Activated Slags. Elsevier, Cement and Concrete Research, Volume 40, pp. 898-907.

[40] S. Ali, R. Dickerson, C. Bennett, P. Bixenman, M. Parlar, C. Price-Smith, S. Cooper, J. Desroches, B. Foxenberg, K. Godwin, T. McPike, E. Pitoni, G. Ripa, B. Steven, D. Tiffin, and J. Troncoso, (2001). High-Productivity Horizontal Gravel Packs. Oilfield Review, Summer 2001, pp. 52-73.

[41] Schlumberger, (2014). Schlumberger Oilfield Glossary - Productivity index. http://www.glossary.oilfield.slb.com/en/Terms/p/productivity_index_pi.aspx.

[42] Strategic Oil Solutions, (2013). Single String Retrievable Hydraulic/Hydrostatic Set. http://strategicoils.com/hydraulicset.html.

[43] T. Sugama, (2006). Advanced Cements for Geothermal Wells. Brookhaven National Laboratory, Energy Sciences and Technology Department/Energy Resources Division, Upton, NY, USA.

[44] J. Tester, (2006). The Future of Geothermal Energy, Impact of Enhanced Geothermal Systems (EGS) on the United States in the $21^{\text {st }}$ Century, Massachusetts Institute of Technology, p. 372.

[45] TPCO China, (2010). OCTG Premium Connections. http://tpcointl.com/Products/Premium+Connection-C39.aspx. Tianjin Pipe International Economic \& Trading Corporation.

[46] W. Renpu, (2011). Advanced Well Completion Engineering, Third Edition. Gulf Professional Publishing, Waltham, Massachusetts, USA. 
[47] Weatherford, (2011). Weatherford FlowMax Sand-Jet Perforator. http://www.weatherford.com/dn/WFT185361.

[48] Weatherford, (2013). Weatherford SS-GDA ICD SuperShiftableTM Gravity Drainage Accessories. Neil Blair, Weatherford internal document, Calgary, Alberta, Canada.

[49] X. Weng, O. Kresse, D. Chuprakov, C.E. Cohen, R. Prioul, and U. Ganguly, (2014). Applying Complex Fracture Model and Integrated Workflow in Unconventional Reservoirs. J. Pet. Sci. Eng., Volume 124, pp. 468-483.

[50] Y. Polsky, L. Capuano Jr., J. Finger, M. Huh, S. Knudsen, A.J. Mansure, D. Raymond, and R. Swanson, (2008). Enhanced Geothermal Systems (EGS) Well Construction Technology Evaluation Report. Sandia National Laboratories, Albuquerque, New Mexico. 